\title{
ENERGY AND INDOOR ENVIRONMENTAL PERFORMANCE OF TYPICAL EGYPTIAN OFFICES: SURVEY, BASELINE MODEL AND UNCERTAINTIES
}

\author{
Aly M. Elharidi 1,2,*, Paul G. Tuohy ${ }^{1}$, Mohamed A. Teamah² ${ }^{2}$ Ahmed A. Hanafy ${ }^{2}$ \\ ${ }^{1}$ University of Strathclyde, Energy System Research Unit [ESRU], Glasgow, United Kingdom \\ ${ }^{2}$ Arab Academy for Science, Technology \& Maritime Transport, College of Engineering and \\ Technology, Alexandria, Egypt. \\ *Corresponding author. Tel: +201006078383, Fax: +2034273415, E-mail: \\ aly.elharidi@strath.ac.uk, alyelharidi@aast.edu.
}

\begin{abstract}
Egyptian electricity demands have increased in recent years and are projected to grow further with significant economic and social impacts. Recently, mandatory and voluntary building codes based on international standards have been increasingly adopted. The performance of existing Egyptian buildings is not well understood making the impact of these new codes uncertain. This paper aims to provide insights into existing Egyptian building performance, and elaborate a process for developing a representative model to assist in future policy. The work presented is for office buildings but intended to be widely replicable. An energy survey was carried out for 59 Egyptian offices, categorised by building service type, it was observed that energy use increases as building services increase, and existing Egyptian offices use less energy than benchmarks. A more detailed investigation for a case study office was carried out, to inform detailed model calibration. This provided insight into energy use, thermal comfort and environmental conditions, and revealed high variability in behaviours. A calibrated model was created for the case study office, then a baseline model and input parameter sets created to represent generalised performance. Future uses including assessment of the impact of codes are discussed, and further replication potentials highlighted.
\end{abstract}

KEYWORDS: Building Performance, Egyptian, Energy, Indoor Environment, Thermal Comfort, Stock Modelling, Simulation, Calibration, Uncertainty.

\section{INTRODUCTION.}

In common with many other nations' Egyptian peak and base load electricity demands have increased greatly since the 1990s, contributing to increasing occurrence of power cuts and blackouts with significant economic, political and social impacts. One key driver for demand growth has been increased urban development concentrated in the Nile Delta [1]. This development was not required to meet any energy performance standards until 2005 with the introduction of the new code, Egyptian Commercial Buildings Energy Code ECP 306-2005[2]. Urban development resulted in particular problems with cooling demands in summer months, associated also with a shift from traditional vernacular designs[3].

The Egyptian Government initially responded through implementation of an integrated energy strategy aiming to reduce energy demand, and to provide the secure, reliable and affordable energy services required to support economic stability and development [4]. Political instability has limited progress but there has recently been a renewed focus with the introduction of new building design codes largely based on existing international (ASHRAE, ECP)[5],[6], the adoption of voluntary international sustainability rating systems such as LEED [7], and introduction of Egyptian sustainability rating systems such as Green Pyramid [8].

Potential concerns with the adoption of these new standards are: (i) that the current energy performance of Egyptian buildings is not well known so the change in performance from adoption of these new design standards is therefore uncertain; (ii) that the appropriateness of these new build design standards to the Egyptian context (weather, customs) has not been fully explored; and (iii) that the new standards do not apply to existing buildings but improvement measures for existing buildings must be an essential part of reducing overall demand. To be able to address these concerns, and appropriately inform future strategy, it would appear to be essential to first characterise the energy and indoor environmental performance of the existing building stock. Many building types make up the stock, in this work, the main focus is on typical Egyptian offices of which there are many, which are naturally ventilated, cooled using unitary air condition systems, and were built prior to the introduction of energy standards in regulations, but other categories of office are also covered. 
The intent of the work presented in this paper then is to contribute to the required performance characterisation for current Egyptian offices. General aims are to, first provide useful insights into existing building performance, and then to elaborate a process leading to creation of a representative model that can be used to inform future policy for such buildings. The work presented covers a single building category but the process is intended to be replicable for other building types.

Various methods have historically been used to represent energy and environmental performance of buildings ranging from statistical black box to detailed physical models Clarke (2001) [9], Reedy \& Andersen (2002) [10], Zhao \& Magoules (2012) [11], Attia (2012) [12]. Dynamic simulation models are increasingly frequently used, these models represent physical behaviour at various levels of detail [13], [14]. At the same time dynamic simulation is used to underpin performance standards such as the EU Energy Performance of Buildings Directive (EPBD) [15] and the UK Building regulations [16] etc. and has been widely used to inform future building strategies [13]. There are many commercial and open source dynamic simulation tools [17], with different characteristics [18]. In this work the IES-VE 2014 dynamic simulation tool was selected as appropriate, it has worldwide accreditation and is used to support numerous regulatory and voluntary standards [19].

For any modelling method it is vital that the model is calibrated, otherwise the results will be unreliable [20]. To address this, calibration processes for building performance models have been a research focus in recent years [14],[16],[21]. ASHRAE Guideline 14-2002 [22] provides standard methods for building calibration and uses Mean Bias Error (MBE) (\%), and Coefficient of Variation of Root Mean Square Error CV(RMSE) (\%) for quantification. In this work a calibration approach based on the ASHRAE Guideline, Coakely (2011) [23] and the work of Reftrey (2011) [24] was used. In this approach a best guess model is constructed based on available data, uncertain parameters are then screened to quantify relative influence, then their values adjusted sequentially in order to minimise errors [25].

It is essential to have actual measured building performance data to inform modelling and feed the model calibration process. There are many building performance datasets available worldwide e.g.UK probe and Energy Consumption studies [26],[27], US Building Performance Studies[28] These are used for model calibration and to inform benchmarks and default parameters for current regulatory compliance tools (e.g. EN15252, UK NCM [29]). It is common practice to categorise office buildings by type e.g. the UK Energy Conservation Guide 19 (ECG 19) [27] categorises offices into 4 types based on form, function, and service strategy, and gives typical and best practice values for different energy use categories (Table 1). Crawley gives the electricity usage for US offices as ranging between 226 and $317 \mathrm{kWh} / \mathrm{m}^{2}$ p.a.[13]. There is some limited data for the Egyptian context. Abdelhafez [30] has gathered monthly electric bill data for a single head office in Cairo over 2 years and gives $202 \mathrm{kWh} / \mathrm{m} 2$ p.a. as the total annual energy use (all electric) and $162 \mathrm{kWh} / \mathrm{m}^{2}$ p.a. for the office equipment, lighting and HVAC. Ezzeldin (2011) [31] modelled cooling strategies for a single prototypical office building in Cairo, Egypt, and gives mixed mode energy use ranging from 70 to $100 \mathrm{kWh} / \mathrm{m}^{2}$ p.a. and central HVAC averaging $170 \mathrm{kWh} / \mathrm{m}^{2} \mathrm{p} . \mathrm{a}$. depending on internal gains scenario. The model was based on many variables like the lighting density, equipment density estimated using standards and codes rather than measured. In general, there is a shortage of measured data for the Egyptian office context.

Table 1. UK Energy Conservation Guide 19 - Energy use in offices (kWh/m² p.a.) [27]

\begin{tabular}{|c|c|c|c|c|c|c|c|c|}
\hline \multirow{2}{*}{$\begin{array}{c}\text { Category of } \\
\text { Office by } \\
\text { Services Type }\end{array}$} & \multicolumn{2}{|c|}{$\begin{array}{c}\text { Naturally Ventilated } \\
\text { Cellular }\end{array}$} & \multicolumn{2}{c|}{$\begin{array}{c}\text { Naturally Ventilated } \\
\text { Open-plan }\end{array}$} & \multicolumn{2}{c|}{$\begin{array}{c}\text { Air-Conditioned } \\
\text { Standard }\end{array}$} & \multicolumn{2}{c|}{$\begin{array}{c}\text { Air-Conditioned } \\
\text { Prestige }\end{array}$} \\
\cline { 2 - 10 } & Practice & Typical & $\begin{array}{c}\text { Good } \\
\text { Practice }\end{array}$ & Typical & $\begin{array}{c}\text { Good } \\
\text { Practice }\end{array}$ & Typical & $\begin{array}{c}\text { Good } \\
\text { Practice }\end{array}$ & Typical \\
\hline Cooling & 0 & 0 & 1 & 2 & 14 & 31 & 21 & 41 \\
\hline Lighting & 14 & 23 & 22 & 38 & 27 & 54 & 29 & 60 \\
\hline Equipment & 12 & 18 & 20 & 27 & 23 & 31 & 23 & 32 \\
\hline Total electricity & 33 & 54 & 54 & 85 & 128 & 226 & 234 & 358 \\
\hline Total heating & 79 & 151 & 79 & 151 & 97 & 178 & 114 & 210 \\
\hline
\end{tabular}

The use of building simulation tools in Egypt was historically low due to not being required for code or regulatory conformance, and the lack of tools in Arabic [32]. The situation is starting to change. There are several recent examples of such tools being used for residential buildings. Attia et al. (2012) [33] developed a representative energy data set and benchmark model for the Egyptian residential sector. Their study included a field survey for apartments in three locations (Alexandria, Cairo and Asyut). Simulation models were created using EnergyPlus software for 2 dwelling types based on the survey data and used to compare the energy consumption per unit area for the two models in the three locations. Elharidi et al. (2013) [34] also carried out an investigation of residential 
buildings. Using survey data from Attia et al. (2012) they developed a simulation model in IES-VE software and investigated potential building upgrades with the aim of reducing electrical power consumption. Mahdy \& Nikolopoulon (2014) [35] used Design Builder software (which embeds EnergyPlus) to study the impact of window-wall ratio, glazing and shading devices for different climate change scenarios. Dabaiah et al. (2015) [36] used DesignBuilder for one room in the typical residential apartment of Attia et al. using the same loads and profile to investigate 37 proposed cool roof options. All of these studies were for the residential sector.

In the Egyptian office sector ElDabosy and AbdElrahman (2013) [37] investigated façade designs for a single office using Ecotect. ElMohimen et al. (2005)[38] applied the DOE-2.1E building simulation tool to study daylighting in a specific Egyptian office building. Ezzeldin (2011) [31] examined mixed-mode cooling strategies for an existing modern typical office building located in Cairo using EnergyPlus. Saleem et al. (2016) [39] used DesignBuilder to create a model for natural ventilated typical school based on measured data, they examined indoor comfort conditions and energy consumption. Sheta \& Sharples (2010) [40] used measured data to apply a calibration process for the inside room temperature. Hanna (2013) [41] used building simulation to investigate energy performance for different facades.

These recent survey and building simulation studies illustrate the increasing importance of energy performance of buildings and the growing application of energy performance modelling. While these studies provide some useful insights into existing building performance there remain gaps to be addressed to be able to fully characterise the performance of existing buildings and capture that performance within models to support policy development. The intent in this work is to contribute further to addressing these gaps.

\subsection{Research Gaps, Aims and Approach}

The specific gaps to be addressed within this work are that for existing Egyptian offices: there is a shortage of measured data on energy use; there is very little measured data on indoor environment; there has been only limited use of simulation and formal model calibration methods; no standard process has been established for creating a representative model that incorporates variations in patterns of use and behaviours.

The main aims of the current study are: (i) to provide insights into energy use and indoor environmental quality associated with current Egyptian office buildings, (ii) to elaborate a methodology for producing a model to represent current Egyptian office performance to be used in future to inform upgrades and policy directions.

The key elements presented here in support of these aims are:

1. An energy survey carried out to establish energy use across a range of 59 Egyptian offices categorised according to building service type.

2. A more detailed energy, environmental and behavioural survey for a case study office building was carried out to gather information to inform model creation and calibration.

3. The creation of a calibrated model of the case study office.

4. The elaboration of a process for the generalisation of the model including variations in patterns of use.

These steps are illustrated in Figure 1. The future use of this baseline model in assessment of changes in building standards, building upgrades, weather variations or behavioural changes, and the future application to other building categories or situations is discussed. There are some limitations in the work primarily due to small sample sizes and data availability however it is our assertion that the work provides useful insights and a template for future work to build on. 


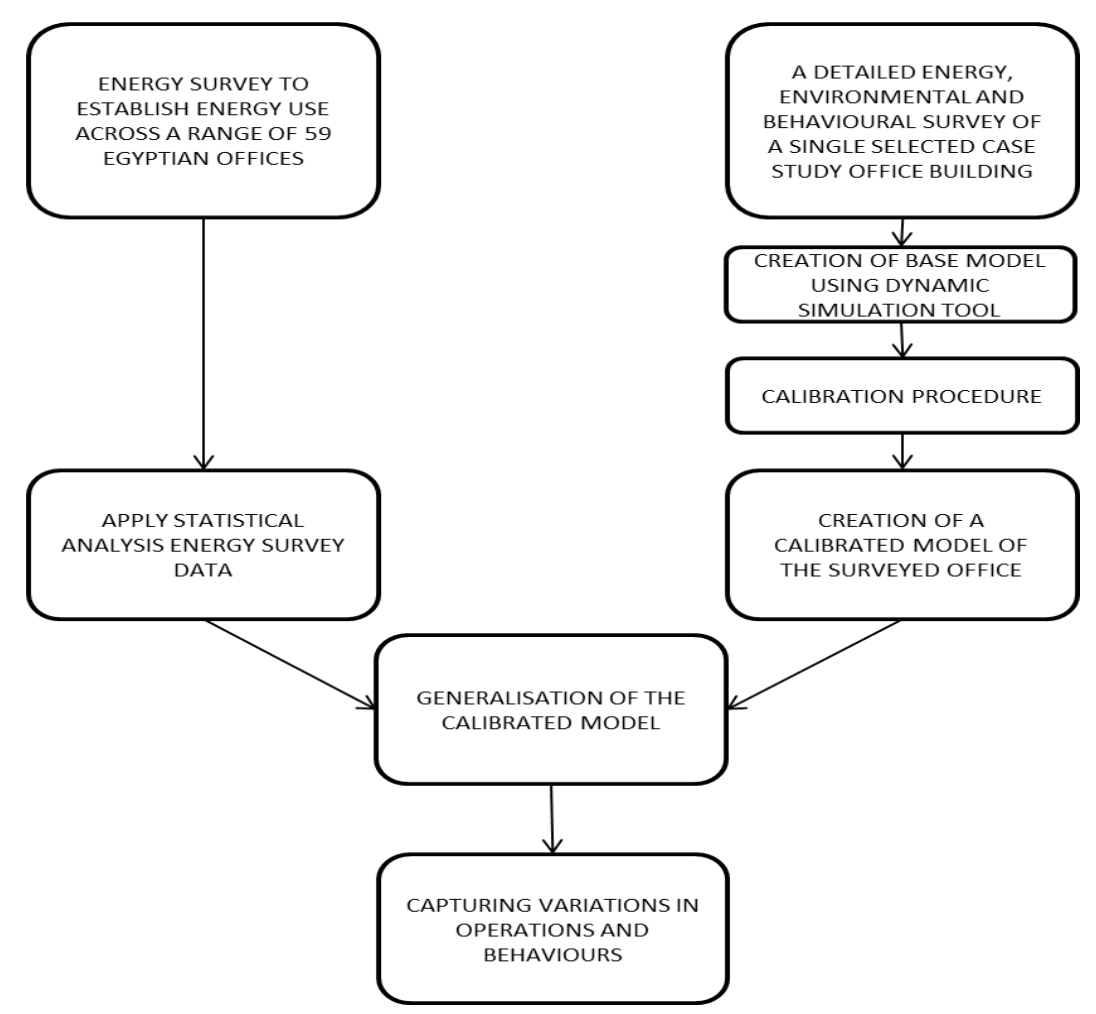

Figure 1. Block diagram summarizing the approach taken in the study.

\section{SURVEY OF ENERGY USE IN 59 EGYPTIAN OFFICES}

To gain a snapshot of energy use a simple field survey was conducted for 59 offices in Alexandria. Data recorded included: office total internal floor area, office business activity, building type, building services type, and electricity bill data for 12 continuous months during 2013-2014. The surveyed offices included lawyers, accountants, travel agents, sales, health administration, insurance, consultants, bank administration, human resources, and Government. Surveyed offices were within both mixed office / residential buildings and in single function multi-floor offices.

The surveyed offices were categorised into 4 types by service strategy as shown in Table 2 and the type of buildings illustrated in Figure 2. Annual energy use is summarised by service strategy in Table 3 and monthly energy use shown in Figure 3 and Figure 4, Table 3 also gives a comparison with the UK ECG19 data for electricity use (the ECG19 energy for space heating has been excluded, as not relevant to the Egypt context). The term 'unitary A/C' is used here as an abbreviation of: 'Local cooling with individual unitary or split cooling systems colloquially known as 'A/C',

The survey only included 2 buildings with central HVAC. To supplement the survey data the published monthly electrical energy data of Abdelhafez [30] and Ezzeldin [31] for this type of Egyptian office is also presented in Table 3. Abdelhafez gives $202 \mathrm{kWh} / \mathrm{m}^{2}$ p.a. as total energy use, and $162 \mathrm{kWh} / \mathrm{m}^{2}$ p.a. for HVAC, lights and equipment over 2 years of monitoring, the difference is possibly infrastructure such as lifts or external security lights. Ezzeldin [31] reported total energy use within the range of 118 to 237 with an average of $170 \mathrm{kWh} / \mathrm{m}^{2} \mathrm{p} . \mathrm{a}$. depending on specific pattern of use. These values are not inconsistent with those measured in the survey.

Table 2. Egyptian office survey overview

\begin{tabular}{|c|c|c|c|c|}
\hline $\begin{array}{c}\text { Office } \\
\text { Type }\end{array}$ & $\begin{array}{c}\text { No. of survey } \\
\text { offices }\end{array}$ & $\begin{array}{c}\text { Ventilation } \\
\text { System }\end{array}$ & Cooling System & Description \\
\hline Type 1 & 7 & $\begin{array}{c}\text { Natural } \\
\text { Ventilation }\end{array}$ & No Cooling & Offices in residential buildings \\
\hline Type 2 & 41 & $\begin{array}{c}\text { Natural } \\
\text { Ventilation }\end{array}$ & Unitary A/C & Offices in residential or multiple floor offices \\
\hline Type 3 & 9 & $\begin{array}{c}\text { Mechanical } \\
\text { Ventilation }\end{array}$ & Unitary A/C & Multi floor office buildings \\
\hline Type 4 & 2 & \multicolumn{2}{|c|}{ Central HVAC } & Multi floor office buildings \\
\hline
\end{tabular}




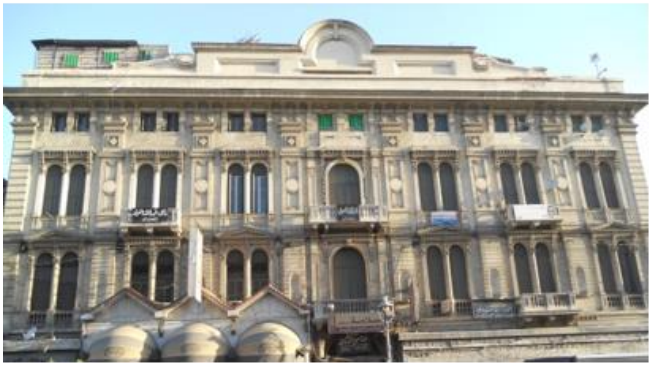

Type 1

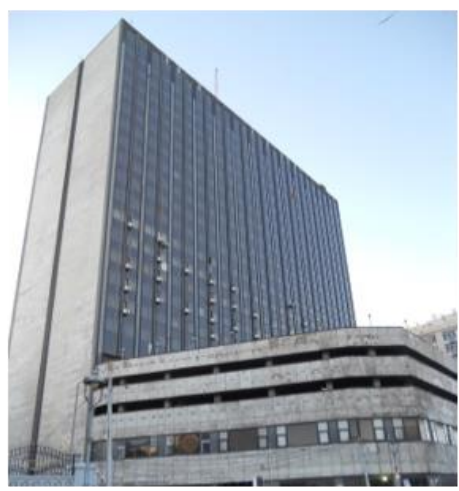

Type 3
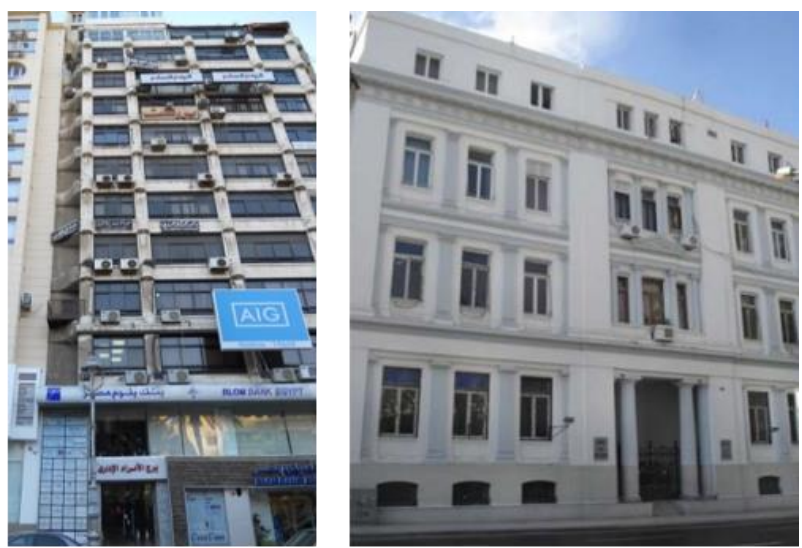

Type 2
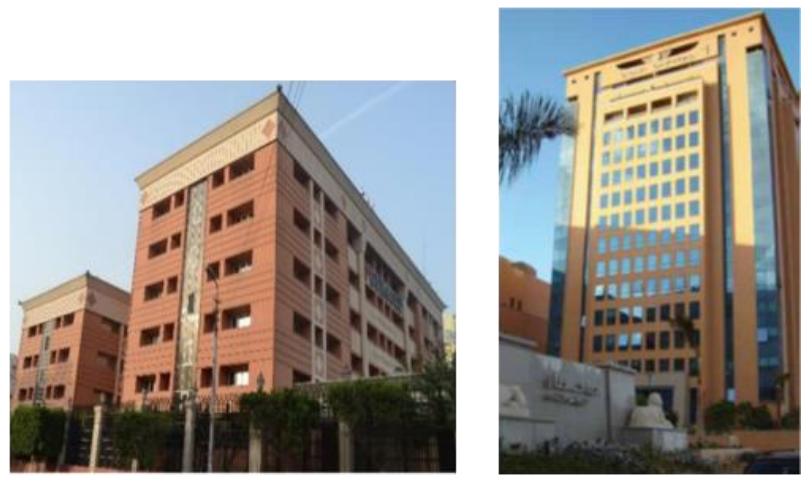

Type 4

Figure 2. Examples of the 4 types of egyptian buildings

Table 3. Average annual electricity consumption for the Egyptian office surveys plus supplementary data from *Abdelhafez [30] and ** Ezzeldin [31]; and comparable ECG 19 [36] data with space heating excluded.

\begin{tabular}{|c|c|c|c|c|}
\hline Category by Services & $\begin{array}{c}\text { Natural } \\
\text { Ventilation } \\
\text { (type 1) }\end{array}$ & $\begin{array}{c}\text { Natural Ventilation } \\
\text { and 'A/C' Unitary } \\
\text { Cooling } \\
\text { (type 2) }\end{array}$ & $\begin{array}{c}\text { Mechanical } \\
\text { Ventilation and } \\
\text { Unitary 'A/C' } \\
\text { (type 3) }\end{array}$ & $\begin{array}{c}\text { Mechanical } \\
\text { Ventilation and } \\
\text { Central HVAC } \\
\text { (type 4) }\end{array}$ \\
\hline Annual average $\mathrm{KWh} / \mathrm{m}^{2}$ & 23 & 40 & 67 & $162^{*}, 118 / 237^{* *}$ \\
\hline $\begin{array}{c}\text { ECG19 best practice / } \\
\text { typical }\end{array}$ & $31 / 48$ & $50 / 77$ & $124 / 218$ & $230 / 350$ \\
\hline
\end{tabular}



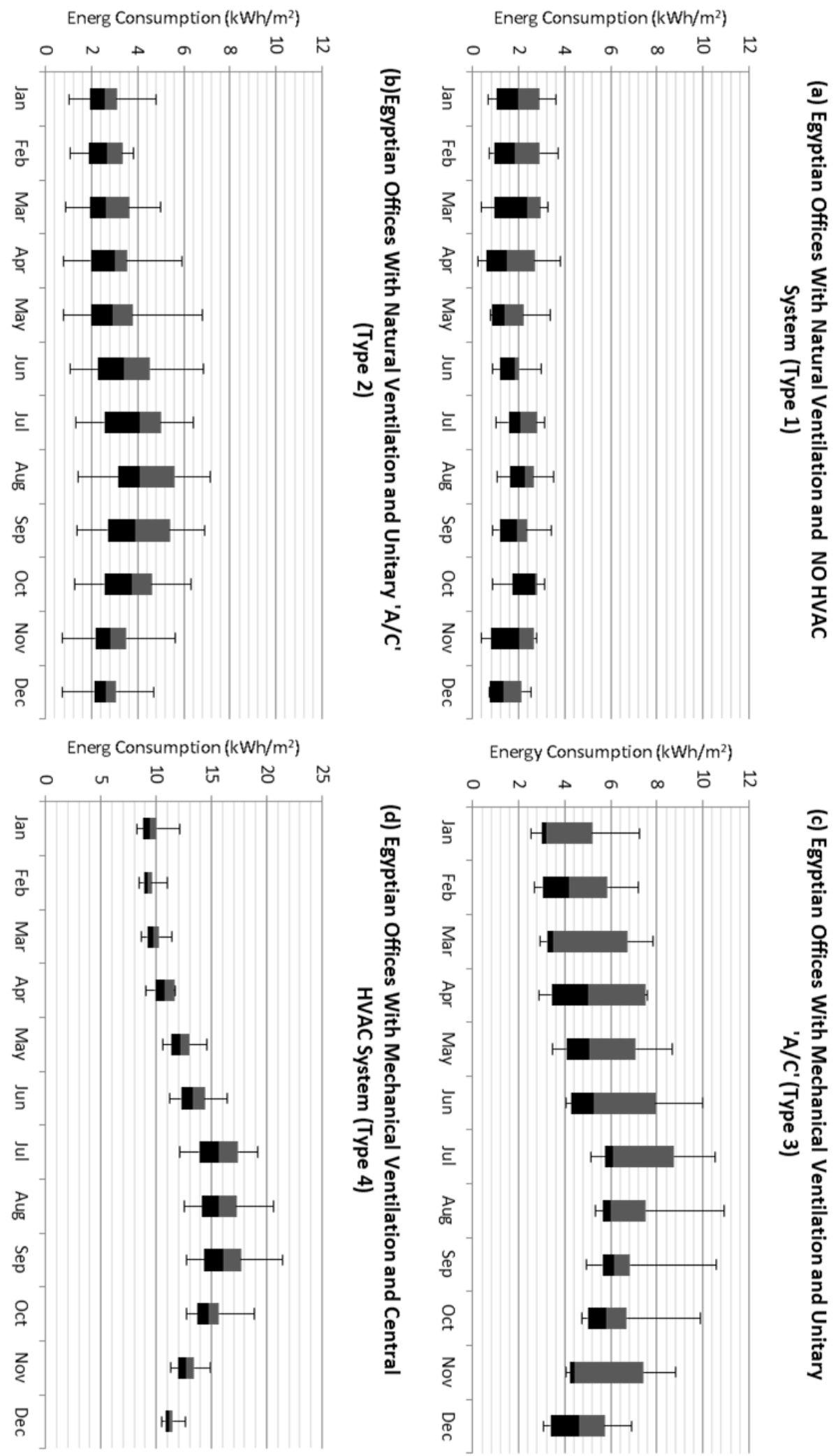

Figure 3. Monthly energy consumption (solid shapes are $+/-25$ percentiles, lines the range) for Egyptian offices: (a) with natural ventilation and no cooling, (b) with natural ventilation and unitary cooling ' $\mathrm{A} / \mathrm{C}$ ', (c) with mechanical ventilation and unitary ' $\mathrm{A} / \mathrm{C}$ ', and (d) with mechanical ventilation and central ' $\mathrm{A} / \mathrm{C}$ ' system. 


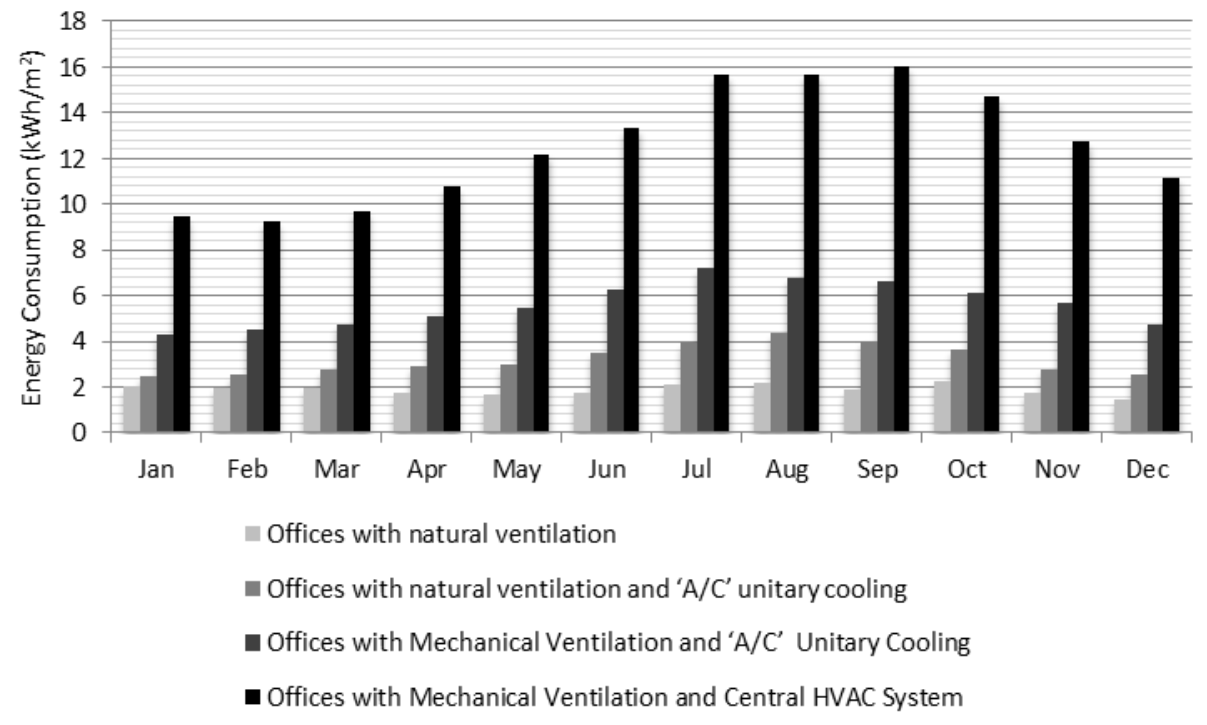

Figure 4. Monthly office energy use vs. service strategy.

The survey data shows that the naturally ventilated offices without cooling have the lowest energy use, those with cooling systems have higher consumption particularly in summer months, offices with mechanical ventilation have higher energy use than those with natural ventilation, and those with centralised cooling or centralised HVAC have the highest consumption. The results show the same trend as in the UK Energy Conservation Guide 19 (ECG 19) [27] as shown in Table 3, where more highly serviced buildings consume higher levels of electrical energy, however it appears that in general the total electrical energy use is lower for the Egyptian offices in the survey than the UK or US benchmarks.

There were many difficulties in gathering the survey data, given the socio-economic situation it was difficult to find building occupants willing to share their energy use data, this limited the quantity of data gathered leaving scope for further work to be done in this area.

While the monthly bill data of the survey provides some useful insight, a more detailed performance survey is required to provide deeper understanding and inform the creation of a representative simulation model.

\section{DETAILED PERFORMANCE EVALUATION FOR A CASE STUDY OFFICE}

The most common office type found in the 59 building survey was 'Type 2 ' with natural ventilation and unitary 'A/C' cooling units. A case study building of this type was identified and a detailed energy and indoor environmental evaluation was then carried out.

The case study building was selected based on factors including: building type and service strategy, work activities; available access to the building and agreement from occupants; availability of plans, construction and systems information, and access to local weather data.

The study was designed to provide sufficient information to inform the creation and calibration of a dynamic simulation model. The steps in the performance evaluation were first to gather general building data, then to carry out a detailed monitoring exercise, and then to establish an appropriate weather dataset.

\subsection{Case study building: location, geometry and initial data gathering}

The office building selected is a University Human Resources (HR) building. The building, constructed in the mid-nineties, serves the "Arab Academy for Science, Technology \& Maritime Transport". Figure 5 and Figure 6 show the location of the building, internal and external views. The building is fairly typical in terms of construction, lighting and cooling, IT and other equipment use, and the general nature of the work activities inside the building. Activities in this building follow the academic calendar with increased activities associated with the conclusion and beginning of the academic year (June and August), activities are also affected by Ramadan which was to coincide with July in the year of the monitoring study. 


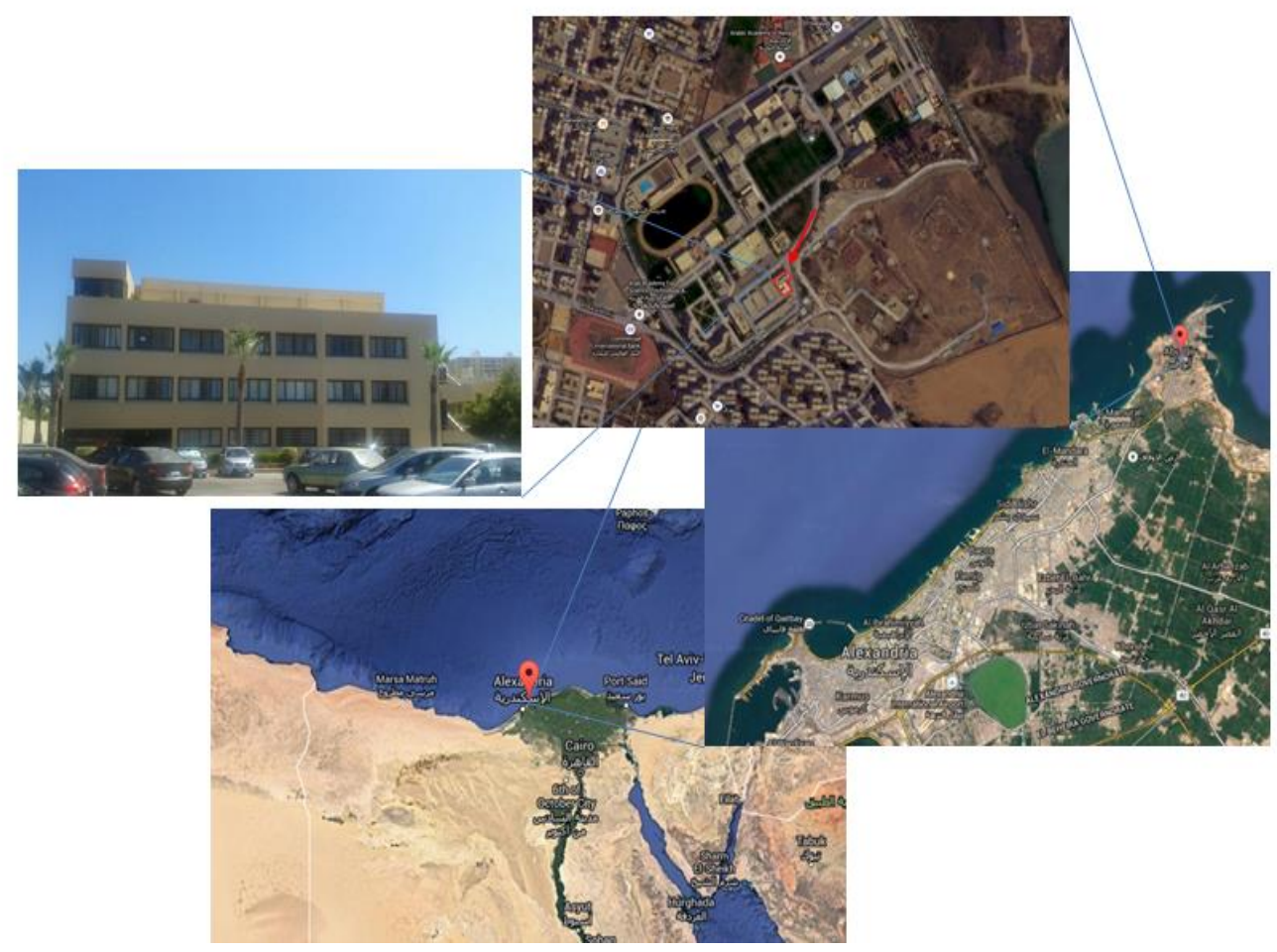

Figure 5. Location and external view of the office building.

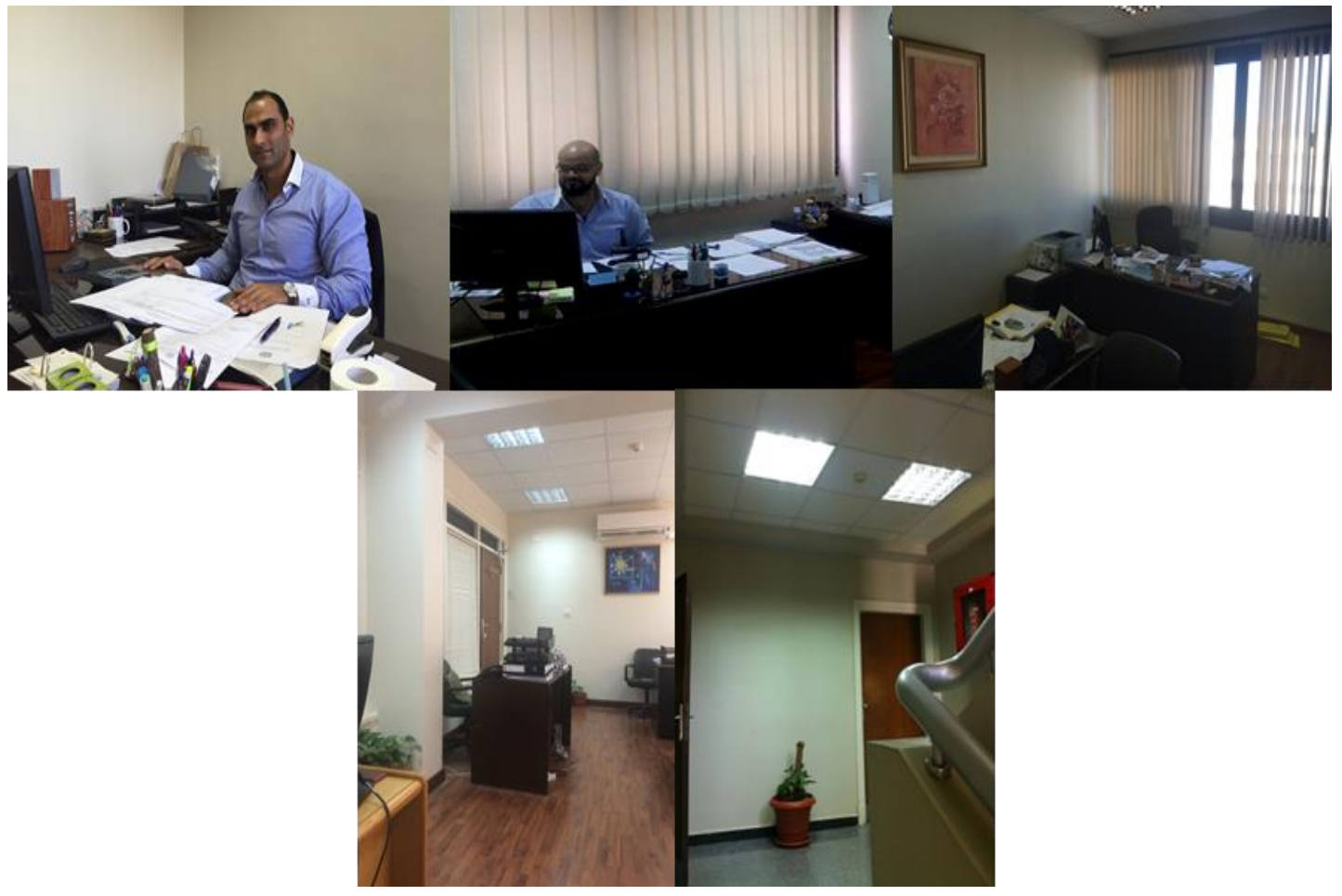

Figure 6. Internal views of the office building

The building has three floors with a central corridor on each. The building floors are almost rectangular shape with total floor area $1090 \mathrm{~m}^{2}$ and 27 cellular office spaces of variable areas, Figure 7 shows layout for one of the building floors, ceiling height is $2.6 \mathrm{~m}$. 


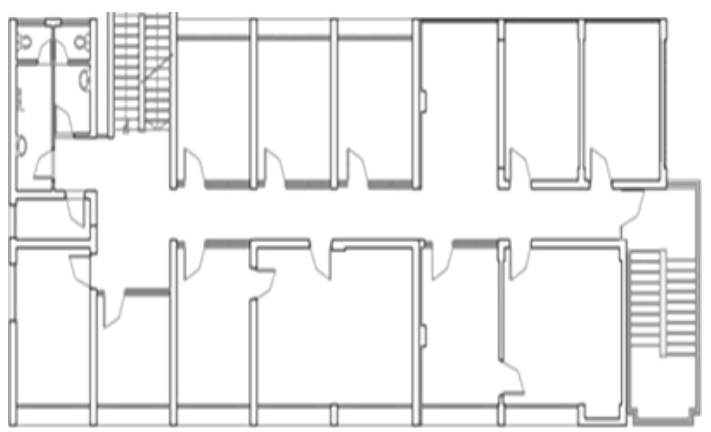

Figure 7. Schematic of office building floor plan.

Initial data was collected for the building (Table 4). This was gathered from available plans, some initial site survey, and calculations of U-values based on construction information, no information was available on thermal bridging or infiltration, thermal bridging was assumed to be included within the elemental U-values, and background infiltration was assumed based on the literature review [31],[40],[42].

Table 4. Initially estimated occupancy, lighting, equipment, HVAC, and construction parameters.

\begin{tabular}{|c|c|c|c|}
\hline \multicolumn{4}{|c|}{ 1. Occupant Density } \\
\hline Density allocated by workstations & \multicolumn{2}{|c|}{1,2 , or 3 persons } & Occupant / Office \\
\hline $\begin{array}{l}\mathrm{m}^{2} / \text { person for larger office spaces, } \\
\text { assumed } 9 \mathrm{am}-5 \mathrm{pm} \text { occupancy. }\end{array}$ & \multicolumn{2}{|l|}{10} & $\mathrm{~m}^{2} /$ person \\
\hline \multicolumn{4}{|c|}{ 2. Lighting } \\
\hline Installed Lighting Load & \multicolumn{2}{|l|}{9.00} & $\mathrm{~W} / \mathrm{m}^{2}$ \\
\hline \multicolumn{4}{|c|}{ 3. Equipment } \\
\hline \multirow{2}{*}{$\begin{array}{l}\text { Installed Equipment Loads : per } \\
\text { workstation for small offices, } \\
\text { density for larger office spaces }\end{array}$} & \multicolumn{2}{|l|}{132.00} & W/Workstation \\
\hline & \multicolumn{2}{|l|}{13.2} & $\mathrm{~W} / \mathrm{m}^{2}$ \\
\hline \multicolumn{4}{|c|}{ 4. HVAC } \\
\hline Cooling set point & \multicolumn{2}{|l|}{23.00} & ${ }^{\circ} \mathrm{C}$ \\
\hline Background infiltration rate & \multicolumn{2}{|l|}{0.60} & $1 / \mathrm{s} . \mathrm{m}^{2}$ \\
\hline \multicolumn{4}{|c|}{ 5. Type of Air Conditioning } \\
\hline Air condition type & Model & Capacity & EER W/W \\
\hline Split & Carrier (42vmc18c) & 2.5 H.P & 2.96 \\
\hline \multicolumn{4}{|c|}{ 6. Construction Material } \\
\hline External Wall U-Value & \multicolumn{2}{|l|}{2.35} & $\mathrm{~W} / \mathrm{m}^{2} \cdot \mathrm{K}$ \\
\hline Internal Wall U-Value & \multicolumn{2}{|l|}{2.31} & $\mathrm{~W} / \mathrm{m}^{2} \cdot \mathrm{K}$ \\
\hline Roof U-Value & \multicolumn{2}{|l|}{0.40} & $\mathrm{~W} / \mathrm{m}^{2} \cdot \mathrm{K}$ \\
\hline External glazing U-Value & \multicolumn{2}{|l|}{6.40} & $\mathrm{~W} / \mathrm{m}^{2} \cdot \mathrm{K}$ \\
\hline External glass solar transmittance & \multicolumn{2}{|l|}{0.82} & --- \\
\hline Glass visible transmittance & \multicolumn{2}{|l|}{0.76} & --- \\
\hline
\end{tabular}

\subsection{Detailed performance evaluation}

To capture building energy and IEQ performance, occupant behaviour, building operations and weather to give a more comprehensive understanding and allow a calibrated model to be generated requires a more detailed investigation.

The parameters to be measured were those identified as critical for building performance and used for model calibration in the literature including: temperature, humidity, energy consumption, and $\mathrm{CO}_{2}$ level [23],[24],[43]. Portable devices were used for data monitoring, as shown in Table 5. Due to cost constraints and difficulty of access, not all spaces in the building could be continuously monitored and devices were moved as required to provide coverage. The electricity supply to the building is through two cables, one for lighting, and the second one for all other loads including cooling systems. The detailed monitoring process started in January 2014 and extended until December 2015. Much data was gathered, highlights are presented here. 
Table 5. Specifications of the monitoring devices used in data gathering.

\begin{tabular}{|c|c|c|}
\hline Monitoring Data & Device & Specification \\
\hline Space temperature $\left({ }^{\circ} \mathrm{C}\right)$ & Tiny tag - TGU-4500 & $\begin{array}{c}\bullet \text { Measurement ranges }\left(-40^{\circ} \mathrm{C} \text { to } 85^{\circ} \mathrm{C}\right) \\
\text { - Accuracy }\left( \pm 0.6{ }^{\circ} \mathrm{C}\right)\end{array}$ \\
\hline Space relative Humidity $(\%)$ & Tiny tag - TGU-4500 & $\begin{array}{c}\bullet \text { Measurement ranges }(0 \% \text { to } 95) \\
\bullet \text { Accuracy }( \pm 3 \% \mathrm{RH})\end{array}$ \\
\hline Space $\mathrm{CO}_{2}$ levels $(\mathrm{ppm})$ & Extech CO210 & $\begin{array}{c}\bullet \text { Measurement ranges }(0 \mathrm{ppm} \text { to } 9,999 \mathrm{ppm}) \\
\bullet \text { Accuracy }( \pm 1 \mathrm{ppm}) \\
\text { E Device also records Space Temperature }\end{array}$ \\
\hline Electrical energy consumption & WattNode Pulse & $\begin{array}{c}\bullet \text { Measures }(1,2, \text { or } 3 \text { phases }) \\
\text { - Accuracy }( \pm 0.5 \%)\end{array}$ \\
\hline
\end{tabular}

Occupants in this type of building have personal control over their environment through adjustments in A/C on/off switch and set-point temperatures, adjustments to windows, doors or blinds, etc. Occupant behaviour affects energy use and indoor environmental conditions through these personal control actions and also through the use of lighting, computers, and other equipment which consume electricity and contribute heat gains. Large variations in user behaviour were observed.

Several offices were monitored internally for indoor environment (temperature, humidity and carbon dioxide) including offices S02, S07 and S08 on the second floor and F10 on the first floor, these offices are used here to illustrate the office to office and time to time variability in behaviours observed. In addition to physical measurements; parameters such as cooling system setpoint, occupancy, and clothing level were directly observed during periodic visits. Office S08 was selected as representative of the most prevalent 'typical' or 'average' occupied behaviour while the other offices illustrate observed variations from this.

Highly variable patterns of air-conditioner use and indoor temperature were observed. Figure 8 illustrates a range of the different observed behaviours: Figure 8 (a) and Figure 8 (b) show two different offices in august, both cool their offices continuously during the day but with very different achieved temperatures of around 17 and $24^{\circ} \mathrm{C}$ respectively; Figure 8 (c) shows observed behaviour in winter where the cooling was set on at arrival and then turned off after approximately two hours. Capturing the observed variability in user behaviour modelling would appear to present a challenge. The most commonly observed behaviour i.e. similar to office S08, was to set the $\mathrm{A} / \mathrm{C}$ set point temperature at $21^{\circ} \mathrm{C}$, the actual measured temperature achieved would then depend on the energy balance within the space, the placement of the $\mathrm{A} / \mathrm{C}$, and placement of the measurement device within the space.

The relative humidity for different offices was monitored and found to vary between $40 \%$ and $80 \%$ in summer when the $\mathrm{A} / \mathrm{C}$ is operating $65 \%$ and $80 \%$ in winter when the $\mathrm{AC}$ is not operated. Measured $\mathrm{CO}_{2}$ levels inside the office spaces provides an indirect indicator for both occupant density and occupancy schedule although confounded by air change rate. Figure 9 shows $\mathrm{CO}_{2}$ levels inside the same office that nominally has two occupants for two separate periods, illustrating high variability.

External observations were taken to quantify use of windows and blinds. Similar to other behaviour dependent parameters high variability was observed. The office highlighted in Figure 10 (a) and Figure 10 (b) has different window and blind configurations on different days, Figure 10 (c) shows that blinds and windows are in various positions during a winter day. It was observed that in general the windows were predominantly closed in summer when the $\mathrm{A} / \mathrm{C}$ is turned on. In intermediate and winter seasons, the windows were sometimes opened, less frequently on cooler days. 
(a) Office SO2 (21/8/2014)

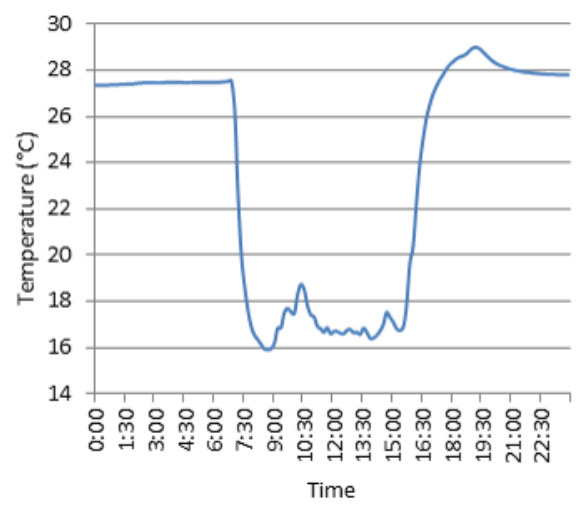

(b) Office S08 (19/8/2014)

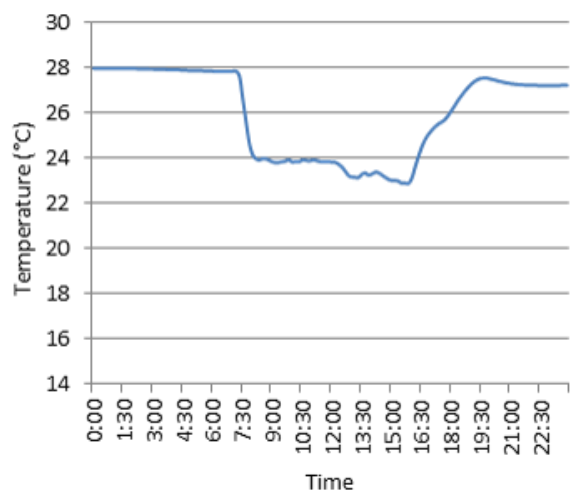

(c) Office F10 (12/11/2014)

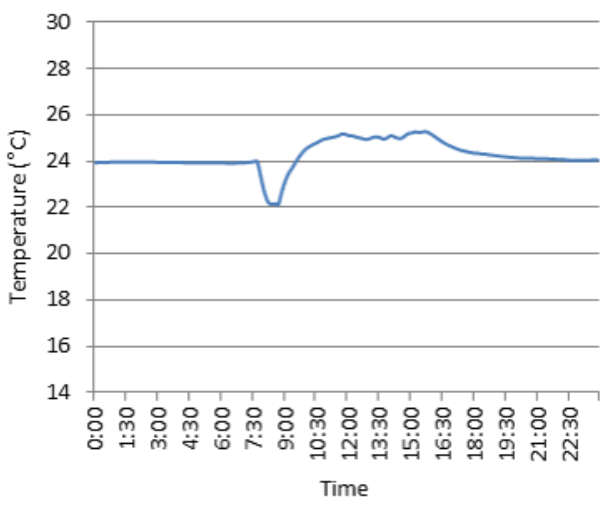

Figure 8. Measured inside room temperature during the day for; (a) office S02 in August, (b) office S08 in August, and (c) office F10 in November

(a) Office $\mathrm{S08}$ (1/11/2014 -6/11/2014)

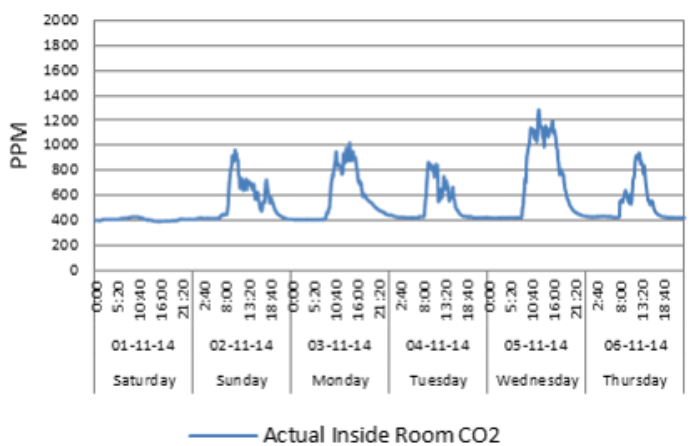

(b) Office S08

(1/12/2014 - 6/12/2014)

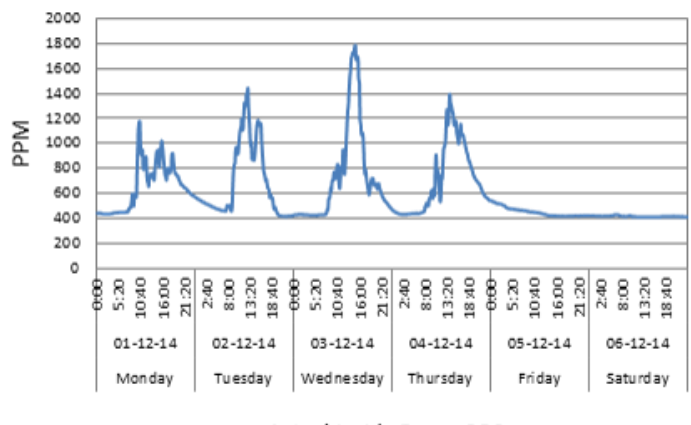

Figure 9. Inside room CO2 level for one of the offices during; (a) first week of november (2014), and (b) first week of december (2014). 
(a)

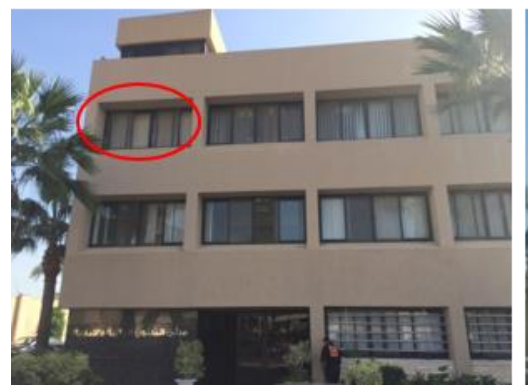

(b)

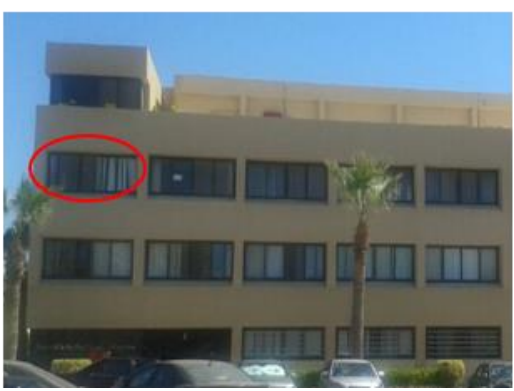

(c)

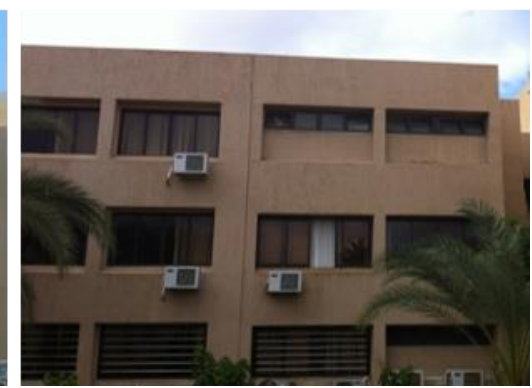

Figure 10. (a) Front side of the building on 07/10/14, (b) Front side of the building on 14/10/14, and (c) Back side of the building on 12/11/14.

The examples discussed above illustrate the variability seen in the monitoring study. Office S08 did appear however to have consistent behaviour with reasonable correspondence in thermal environment with that found in literature [44],[45],[46],[47].

Clothing levels were estimated to be 0.7 CLO in summer and 1.0 in winter with gradual change in transition periods assumed. Figure 11 shows the measured inside dry resultant temperature for periods when S08 was being measured and its correspondence with the calculated neutral temperature using the Predicted Mean Vote (PMV) equations [48] and an estimate of the mean radiant temperature from building simulation modelling (the model will be described in the following sections). Other adaptive comfort criteria [44],[49] were evaluated but PMV gave the best fit and should be used to represent occupant preference in this work [50].

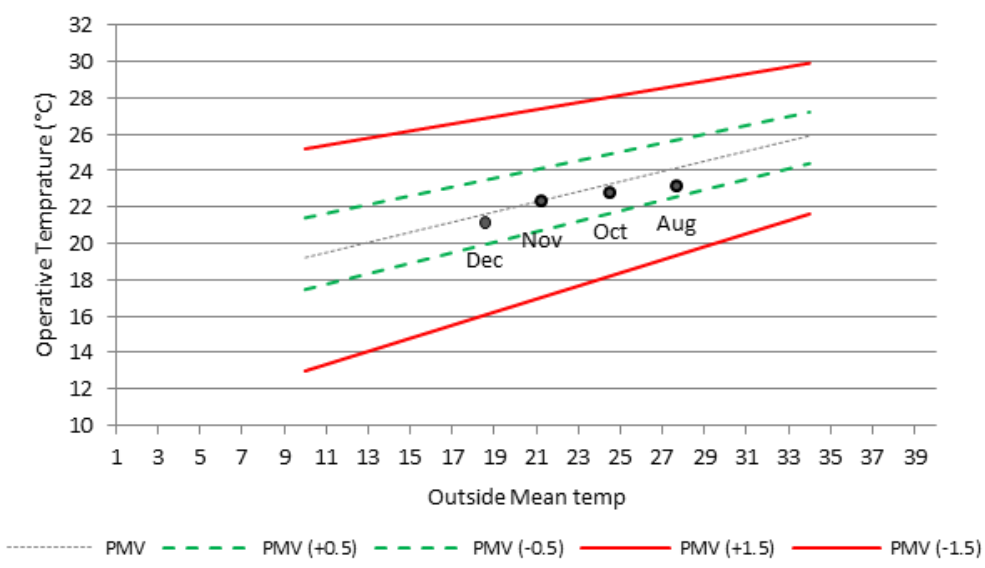

Figure 11. Measured internal conditions for typical office (S08) and PMV comfort criteria versus outdoor mean temperature.

The stochastic variations in behaviours highlighted in this section affect operations, indoor environment and energy use. These variations are challenging to capture in a representative model. Yet it is essential that they are taken into account to ensure the factors behind these variations are represented.

The approach developed in this work to address this problem is first to develop a calibrated model of the specific monitored office building for 'average' behaviour, then to generalize the model to be more representative of the general type 2 offices from the multi-office survey, and finally to capture the likely ranges of operations and behaviours in appropriate sets of input parameters so they can be represented in modelling exercises.

\subsection{Weather}

The weather for the case study building is important to establish as the backdrop for the performance evaluation and for inclusion in modelling. Alexandria's climate is characterized by a winter moderate season with average temperature around $18{ }^{\circ} \mathrm{C}$ and a summer hot season with average temperature around $28^{\circ} \mathrm{C}$. Hourly temperatures 
and humidity's for the Alexandria location of the case study office for 2014, measured at a nearby weather station are shown in Figure 12 Normally the temperatures are between 10 and $32^{\circ} \mathrm{C}$ and humidity between 40 and $90 \%$ in this coastal location, however there are occasional sandstorms that occur due to hot winds, known as Khamsin winds that are equivalent to the sirocco winds in Europe. These sandstorms may occur for periods of up to a few days and can lead to a temperature rise of $20^{\circ} \mathrm{C}$ in 2 hours [51].

An Egyptian Typical Methodology Year (ETMY) weather file based on long term climate analysis is available for use in building design and dynamic simulation studies for the Alexandria region. This includes the full range of weather parameters such as wind, cloud and solar radiation etc. in addition to temperature and humidity [52]. To have a simulation weather file more representative of the actual weather during the monitoring period the measured temperature and humidity from the nearby weather station were superimposed on the ETMY weather file. It would have been ideal to have a full set of measured parameters sufficiently detailed to form a detailed (sub-hourly) simulation weather file but this was not available. Others are investigating methods for synthesising detailed weather files from limited measurement sets [13],[53], but the limitation in the work presented here remains to be addressed in future. Figure 13 gives a comparison of average temperature for the ETMY and the modified simulation weather file used to represent the weather in the model calibration exercise.

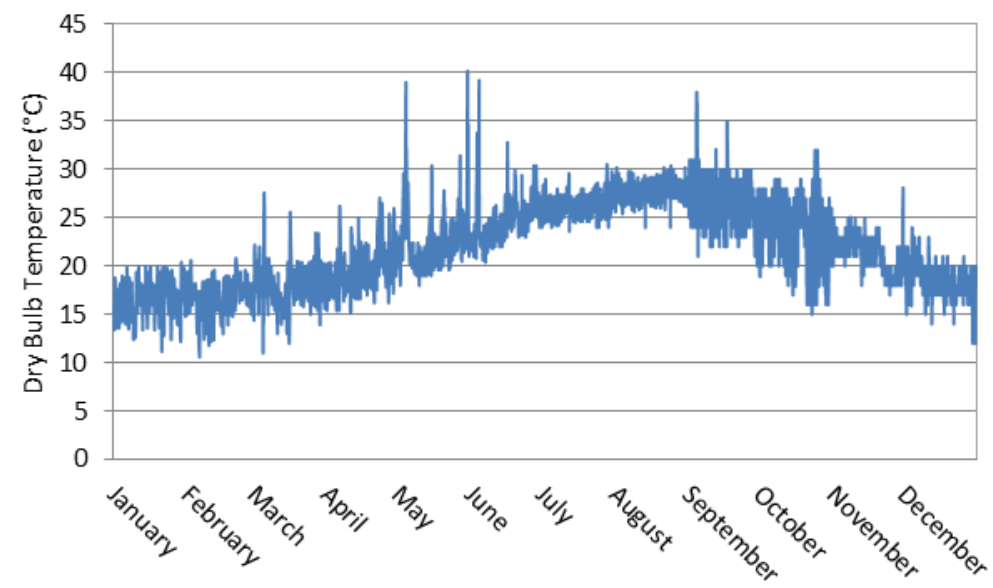

Figure 12. Weather data of Alexandria-Egypt measured by local weather station for year 2014; (dry bulb temperature)

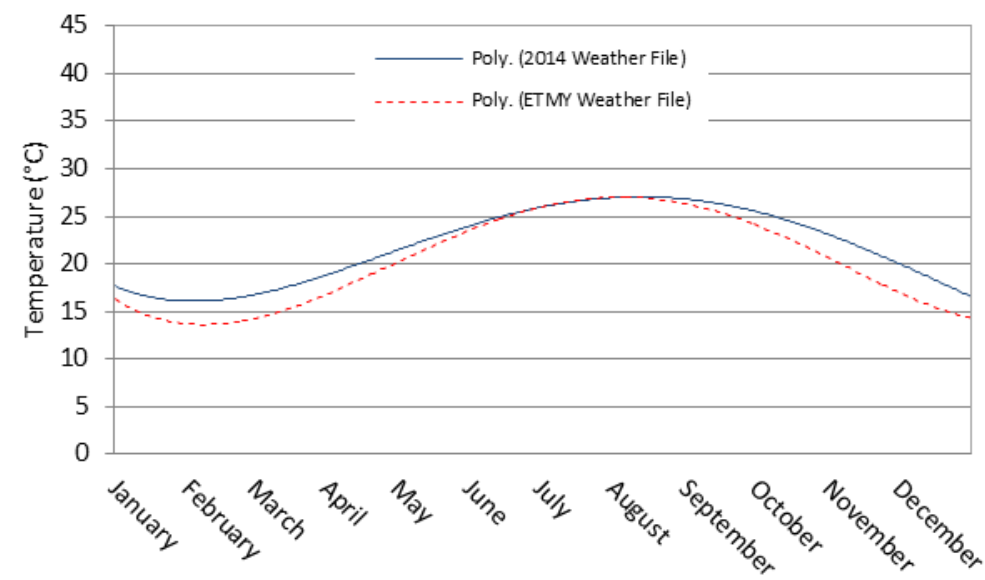

Figure 13. Average dry resultant temperature for Alexandria Egypt (ETMY and Modified Weather file 2014).

\section{A CALIBRATED MODEL OF THE CASE STUDY BUILDING}

In order to capture the performance of the monitored building a calibrated model was created based around the behaviours seen to be most common. The calibration process utilized established calibration techniques and criteria [20],[24],[54]. A base model was defined with initial estimates of uncertain input parameters; a parameter 
screening sensitivity analysis carried out to identify the order of influence of the parameters; then a staged individual parameter adjustment process is executed in the order of decreasing parameter influence.

\subsection{Model calibration process}

In the sensitivity analysis the influence co-efficient (IC) of each parameter is calculated using equation 1 where $\Delta \mathrm{OP}$ and $\Delta \mathrm{IP}$ are changes in output and input, respectively. $\mathrm{OP}_{\mathrm{BC}}$ and $\mathrm{IP}_{\mathrm{BC}}$ are the output and the input base case values, respectively. This sensitivity coefficient is dimensionless and represents the percentage of changing in the output due to a percentage of perturbation in the input.

$$
I C=\frac{\Delta O P \div O P_{B C}}{\Delta I P \div I P_{B C}}
$$

The model is 'calibrated' once a specified level of agreement (or error) is achieved between model-predicted and measured data. The model evaluation statistic used to quantify the error is the CV(RMSD), aggregates time step errors over the runtime into a single dimensionless number, given by equations 2 where $m_{i}$ and $s_{i}$ are measured and simulated data at instance $i$, respectively. In literature, the criteria commonly used to represent acceptable calibration in a situation where there are significant uncertainties e.g. in user behaviour, is a CV(RMSD) of the order of $30 \%$ [14]. The traditional $\mathrm{R}^{2}$ coefficient is also used as a secondary indicator of goodness of fit.

$$
\begin{gathered}
R M S D=\sqrt{\frac{\sum_{i=1}^{n}\left(m_{i}-S_{i}\right)^{2}}{n}} \\
\text { where } C V(R M S D)=\frac{R M S D}{\bar{m}} \cdot 100
\end{gathered}
$$

An initial dynamic simulation model was created from the gathered data presented in section 3 . The case study building model contains about 27 individual office and other ancillary spaces, which are different in areas, number of occupants and equipment.

In the specific simulation software used, the occupancy, lighting, and equipment profiles were established using the installed capacity multiplied by a Modulating Factor (M.F.) representing the daily profile and a Diversity Factor (D.F.) representing the extent to which the modulated capacity is actually in use e.g. at each time step Equipment Load $=$ Installed Equipment x M.F. $x$ D.F. We capture M.F. x D.F. in daily 'profiles' with the occupied period 'Profile Factor (P.F.)' being the extent to which the installed capacity is in use during peak occupancy.

'Winter', 'summer' and 'Ramadan' profiles were differentiated based on the monitored data (Figure 14), the 'summer' profile was applied only to the high activity periods around end May / June and also August / early Sept, 'Ramadan' to July, and 'winter' to the rest of the year. The variation seen in the monitoring data between these periods and indeed on a day to day basis is again striking. The extent to which these profiles are specific to the education support human resources activity in this building is discussed later.

An A/C SEER eff parameter was defined to represent the effective SEER of the cooling systems taking account of the pattern of A/C use across the whole building. The effective SEER is calculated from the cooling system equipment SEER divided by the diversity factor for A/C use within the building, so if only $50 \%$ of the space is being conditioned at that time then SEER eff $_{\text {is }} 2$ x SEER, if only $25 \%$ then 4 x SEER e.g. if SEER is 3.5 and only

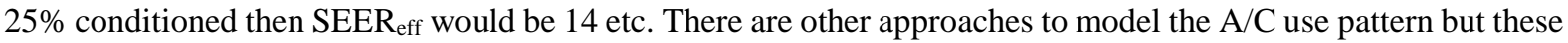
would have required either more extensive monitoring than was possible and correspondingly more detailed modelling. Given the variability seen in section 3 the approach of assigning a SEER eff based on monitoring of cooling energy use and then refining this value through the calibration process was selected as the best approach.

Windows were assumed to be closed during warm periods when the $\mathrm{A} / \mathrm{C}$ is in use, and during cold winter periods when indoor temperatures are below the normal heating setpoint (there is no heating in the building), in transition seasons the windows were assumed to be opened proportionately to achieve comfort cooling.

Once the initial model was constructed a sensitivity analysis was undertaken. The parameters included in the sensitivity analysis were identified based on literature plus initial screening studies, ranges set for these parameters were based on literature[32],[55],[56], and given in Table 6. The model was then used to calculate the Influence Co-efficient (IC) for each main uncertain variable. The influence co-efficient was calculated first with reference to the energy use, then for the indoor temperatures, and then CO2. Table 6 and Figure 15 show the variables with greatest IC for the energy use and indoor temperature which are; A/C set point temperature, lighting loads, equipment loads, A/C SEER eff. For $\mathrm{CO}_{2}$, the variables with greatest IC are; the infiltration and occupancy. 
Occupancy Profiles

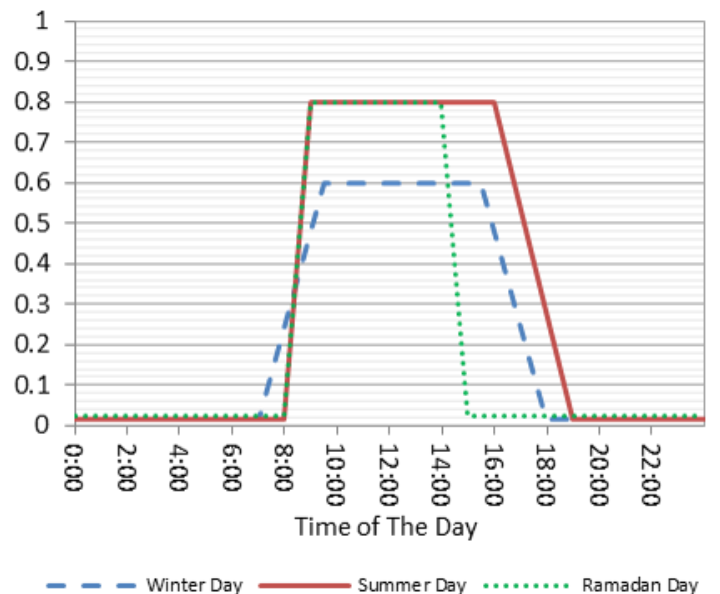

Equipment Profiles

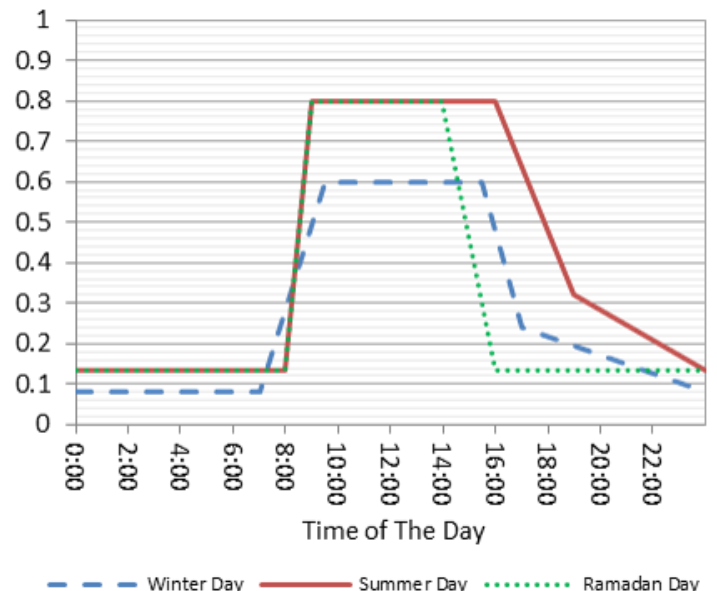

Lighting Profiles

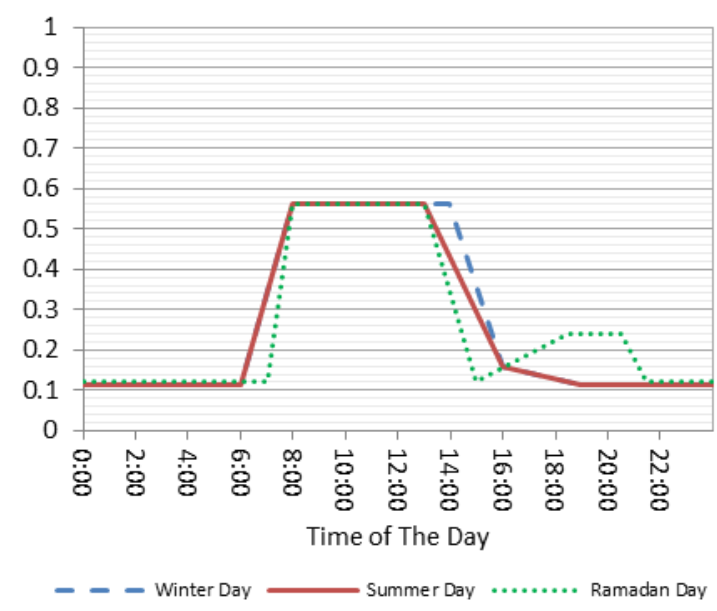

Figure 14. Occupancy, equipment and lighting profiles

Table 6. Ranges of main uncertain variables used in the calibration model.

\begin{tabular}{|c|c|c|c|c|c|}
\hline Variable & Units & Base Case & Minimum & Maximum & IC \\
\hline valiatie & Uimis & Value & Value & Value & IC \\
\hline A/C Control \& Set point & ${ }^{\circ} \mathrm{C}$ & 23 & 18 & 26 & 0.797 \\
\hline Installed Lighting Load & $\mathrm{W} / \mathrm{m}^{2}$ & 9 & 4 & 16 & 0.187 \\
\hline \multirow{2}{*}{ Installed Equipment Load } & W/ Desk space & 132 & 54 & 217 & \multirow{2}{*}{0.142} \\
\hline & $\left(\mathrm{W} / \mathrm{m}^{2}\right)$ & 13.2 & 5.4 & 21.7 & \\
\hline $\mathrm{A} / \mathrm{C} \mathrm{SEER}_{\mathrm{eff}}$ & $\mathrm{W} / \mathrm{W}$ & 3 & 2 & 8 & 0.136 \\
\hline Lighting D.F & --- & 0.8 & 0.2 & 1 & 0.114 \\
\hline External glazing Shading G value & --- & 0.82 & 0.32 & 0 & 0.093 \\
\hline Equipment D.F & --- & 0.8 & 0.2 & 1 & 0.084 \\
\hline External Window U value & $\mathrm{W} / \mathrm{m}^{2} \cdot \mathrm{K}$ & 6.4 & 1.54 & 6.5 & 0.011 \\
\hline Internal Wall U Value & $\mathrm{W} / \mathrm{m}^{2} \cdot \mathrm{K}$ & 2.31 & 1.2 & 3 & 0.009 \\
\hline Infiltration Rate & $\mathrm{L} / \mathrm{S} . \mathrm{m}^{2}$ & 0.6 & 0.3 & 1.3 & 0.007 \\
\hline Roof U value & $\mathrm{W} / \mathrm{m}^{2} \cdot \mathrm{K}$ & 0.4 & 0.13 & 0.9 & 0.004 \\
\hline External Wall U value & $\mathrm{W} / \mathrm{m}^{2} \cdot \mathrm{K}$ & 2.35 & 0.18 & 4.3 & 0.003 \\
\hline Internal Ceiling U Value & $\mathrm{W} / \mathrm{m}^{2} \cdot \mathrm{K}$ & 3.5 & 0.13 & 4 & 0.001 \\
\hline
\end{tabular}




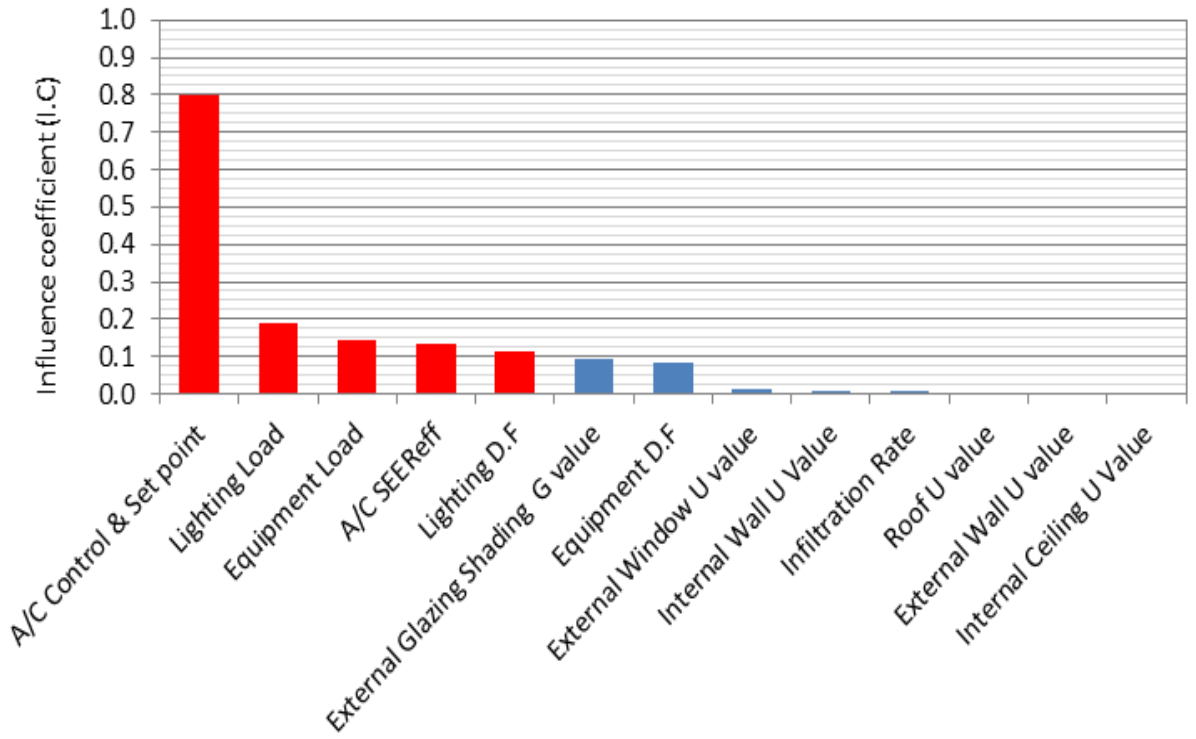

Figure 15. Parametric analysis chart based on the influence coefficient for energy use and indoor temperatures.

After establishing the most influential variables based on IC values, the calibration process was organised into stages. In the first stage, the original base model was used and focus variable group 1 adjusted to give the best fit. In the second stage the updated model used and focus variable group 2 adjusted, and so on. Table 7 summarises the calibration process stages and the calibrated values set for each of the parameters.

Given the high variability seen in the monitoring study being driven by stochastic user behaviours and other uncertainties, the calibration process yielded acceptable results with high $\mathrm{R}^{2}$ and acceptable CV(RMSE). The

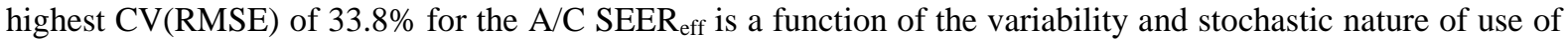
these systems in a building of this type which was not possible to capture better in the model.

Table 7. A summary for the calibration process stages. (Profile factor =D.F * M.F)

\begin{tabular}{|c|c|c|c|c|c|c|c|}
\hline \multirow{2}{*}{\multicolumn{2}{|c|}{$\begin{array}{c}\text { Calibration Stage and Focus } \\
\text { Variable Group }\end{array}$}} & \multicolumn{3}{|c|}{ Primary Variable } & \multirow{3}{*}{$\begin{array}{c}\mathbf{R}^{2} \\
0.97\end{array}$} & \multirow{3}{*}{$\begin{array}{c}\text { CV(RMSE) } \\
7.22 \%\end{array}$} & \multirow{3}{*}{\begin{tabular}{l}
\multicolumn{1}{c}{$\begin{array}{c}\text { Method of } \\
\text { Calibration }\end{array}$} \\
$\begin{array}{l}\text { Based on } \mathrm{CO} 2 \text { level } \\
\text { in one office during } \\
\text { typical working day }\end{array}$
\end{tabular}} \\
\hline & & \multirow{2}{*}{$\begin{array}{l}\text { Unit } \\
1 / \mathrm{s} . \mathrm{m}^{2}\end{array}$} & \multirow{2}{*}{$\begin{array}{c}\begin{array}{c}\text { Initial } \\
\text { Value }\end{array} \\
0.6\end{array}$} & \multirow{2}{*}{$\begin{array}{c}\begin{array}{c}\text { Calibrated } \\
\text { Value }\end{array} \\
1\end{array}$} & & & \\
\hline Stage 1 & $\begin{array}{l}\text { Infiltration rate } \\
\text { and profile }\end{array}$ & & & & & & \\
\hline \multirow[b]{2}{*}{ Stage 2} & \multirow{2}{*}{$\begin{array}{c}\text { Equipment } \\
\text { load and profile } \\
\text { factor }\end{array}$} & $\begin{array}{l}\text { Equipment Load } \\
\left(\mathrm{W} / \mathrm{m}^{2}\right)\end{array}$ & 13.2 & 17.6 & \multirow[b]{2}{*}{0.98} & \multirow[b]{2}{*}{$14.00 \%$} & \multirow{2}{*}{$\begin{array}{c}\text { Based on monitoring } \\
\text { energy consumption } \\
\text { for equipment during } \\
\text { winter (with } \mathrm{A} / \mathrm{C} \\
\text { turned off) }\end{array}$} \\
\hline & & $\begin{array}{l}\text { Winter Profile } \\
\text { Factor }\end{array}$ & 0.6 & 0.6 & & & \\
\hline \multirow{3}{*}{ Stage 3} & \multirow{3}{*}{$\begin{array}{c}\text { Lighting } \\
\text { load and Profile } \\
\text { Factor }\end{array}$} & $\operatorname{Load}\left(\mathrm{W} / \mathrm{m}^{2}\right)$ & 9 & 12 & \multirow{3}{*}{0.93} & \multirow{3}{*}{$21.80 \%$} & \multirow{3}{*}{$\begin{array}{l}\text { Based on monitoring } \\
\text { energy consumption } \\
\text { for lighting }\end{array}$} \\
\hline & & $\begin{array}{l}\text { Summer Profile } \\
\text { Factor }\end{array}$ & 0.55 & 0.35 & & & \\
\hline & & $\begin{array}{l}\text { Winter Profile } \\
\text { Factor }\end{array}$ & 0.55 & 0.45 & & & \\
\hline \multirow{3}{*}{ Stage 4} & \multirow{2}{*}{$\begin{array}{l}\text { A/C profile, Set } \\
\text { point and summer } \\
\text { control }\end{array}$} & ${ }^{\circ} \mathrm{C}$ & 23 & 21 & \multirow[b]{2}{*}{0.84} & \multirow[b]{2}{*}{$3.47 \%$} & \multirow{2}{*}{$\begin{array}{c}\text { Based on monitoring } \\
\text { Office Dry resultant } \\
\text { temperature during } \\
\text { summer }\end{array}$} \\
\hline & & $\begin{array}{c}\text { Glass Shading } \\
\text { Coefficient } \\
\text { (G Value) } \\
\end{array}$ & 0.82 & 0.82 & & & \\
\hline & $\begin{array}{l}\text { A/C profile, Set } \\
\text { point and Winter } \\
\text { Control }\end{array}$ & ${ }^{\circ} \mathrm{C}$ & 23 & 21 & 0.75 & $1.64 \%$ & $\begin{array}{c}\text { Based on monitoring } \\
\text { Office Dry resultant } \\
\text { temperature during } \\
\text { winter week }\end{array}$ \\
\hline \multirow{3}{*}{ Stage 5} & \multirow{3}{*}{$\begin{array}{l}\text { A/C SEER and } \\
\text { average number of } \\
\text { offices using } \mathrm{A} / \mathrm{C} \\
\text { during summer }\end{array}$} & SEER W/W & 3 & 6 & \multirow{3}{*}{0.93} & \multirow{3}{*}{$33.80 \%$} & \multirow{3}{*}{$\begin{array}{l}\text { Based on monitoring } \\
\text { energy consumption } \\
\text { for equipment and } \\
\text { A/C during Summer }\end{array}$} \\
\hline & & $\begin{array}{l}\text { Equipment Load } \\
\left(\mathrm{W} / \mathrm{m}^{2}\right)\end{array}$ & 17.6 & 17.6 & & & \\
\hline & & $\begin{array}{l}\text { Summer Profile } \\
\text { Factor }\end{array}$ & 0.8 & 0.9 & & & \\
\hline Stage 6 & $\begin{array}{l}\text { Final check for } \\
\text { Equipment and } \\
\text { A/C power } \\
\text { consumption } \\
\end{array}$ & --- & --- & --- & 0.95 & $24.40 \%$ & $\begin{array}{c}\text { Based on monitoring } \\
\text { energy consumption } \\
\text { for equipment and } \\
\text { A/C during winter }\end{array}$ \\
\hline
\end{tabular}




\subsection{Calibrated model - results}

The results of the calibration process produced a model that overall gave good agreement to the observed typical measured performance both for indoor environmental properties and overall energy consumption. There were areas of disagreement but this was not surprising given the stochastic behaviour and the limitations in the monitoring and weather data mentioned earlier.

Figure 16 and Figure 19 show measured and simulated CO2 and temperature for typical conditions for the office S08 which was representative of average behaviour in the monitoring study. Figure 16 shows the $\mathrm{CO}_{2}$ level during a typical working week (which is consistent with acceptable levels: 700 to 1000 PPM above outside $\mathrm{CO}_{2}$ level). Figure 19 illustrates measured and modelled inside dry resultant temperature for office S08 during winter and summer periods. The results shows that inside dry resultant temperature matches well during winter week where the $\mathrm{A} / \mathrm{C}$ is not used and during summer week where the windows are normal closed and $\mathrm{A} / \mathrm{C}$ used. There is some disagreement during the transient between occupied and unoccupied hours where some more detailed human behaviour model could potentially be further investigated.

As indicated in Figure 17, there is generally good agreement for the lighting energy consumption. Figure 18 shows combined equipment and $\mathrm{A} / \mathrm{C}$ energy consumption, both measured and simulated, during summer $(\mathrm{A} / \mathrm{C}$ in $\mathrm{use})$ (Figure 18 (a)) and winter (A/C not used) periods (Figure 18 (b)). It could be concluded that the Equipment and $\mathrm{A} / \mathrm{C}$ load in summer periods are three times the winter due to the high use of the $\mathrm{A} / \mathrm{C}$ in summer and due to the nature of the work encountered in the office.

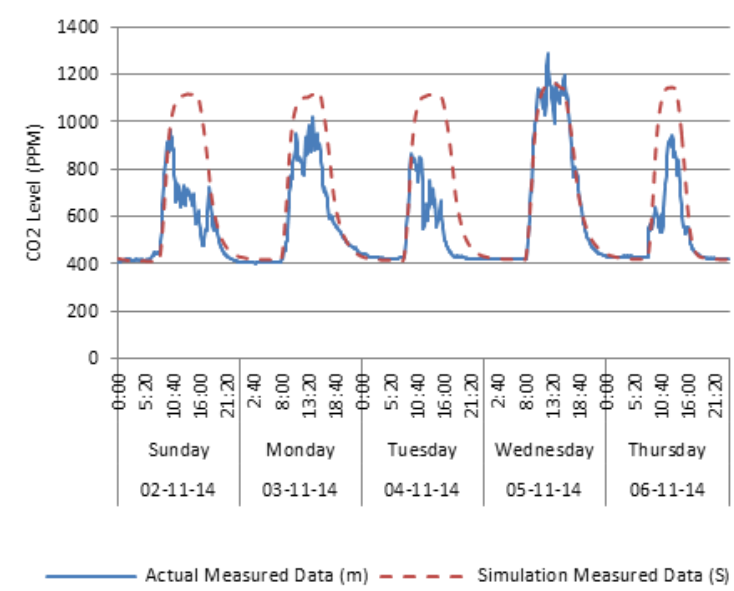

Figure 16. Inside room $\mathrm{CO} 2$ level

(a)

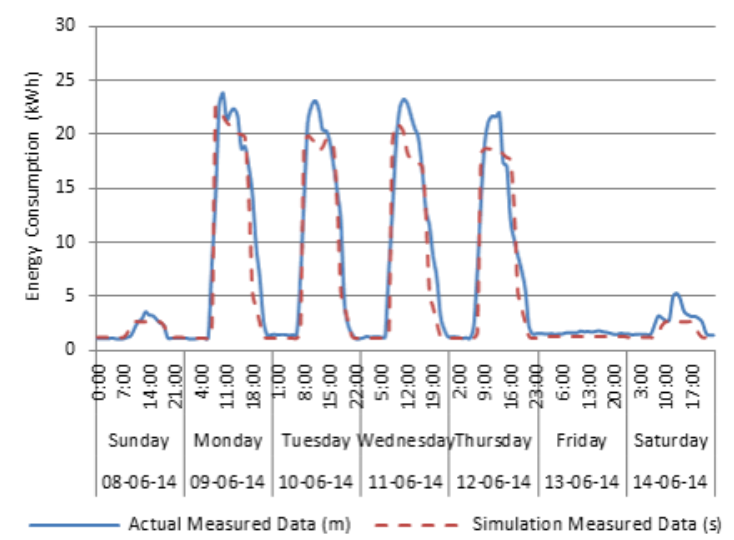

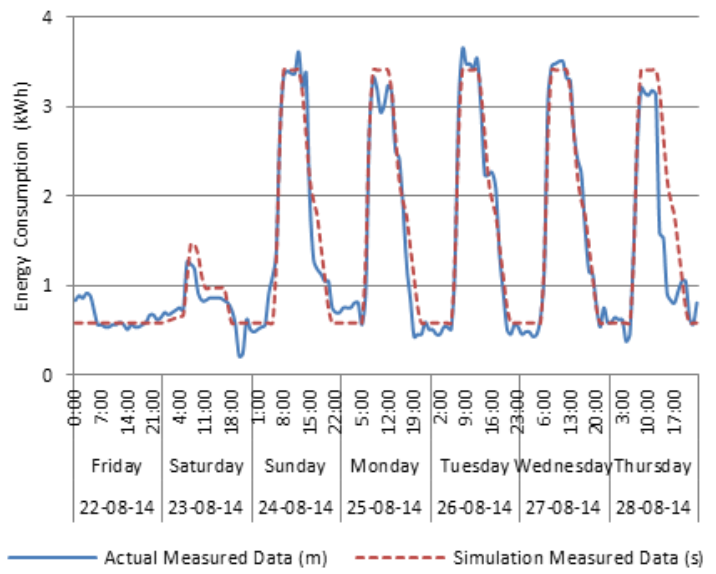

Figure 17 Lighting energy consumption

(b)

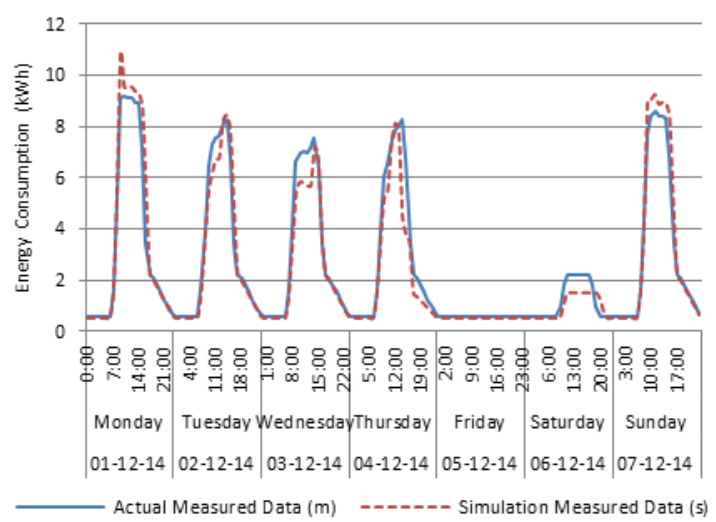

Figure 18. Equipment \& A/C energy consumption for; (a) whole week during summer, and (b) whole week during winter. 
(a)

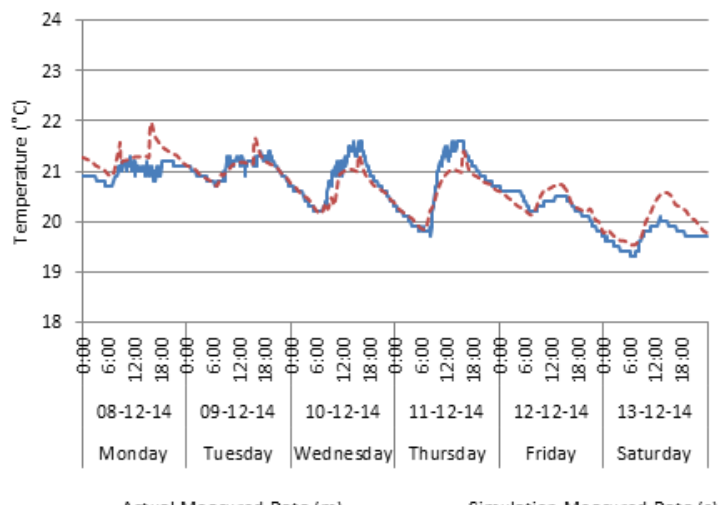

(b)

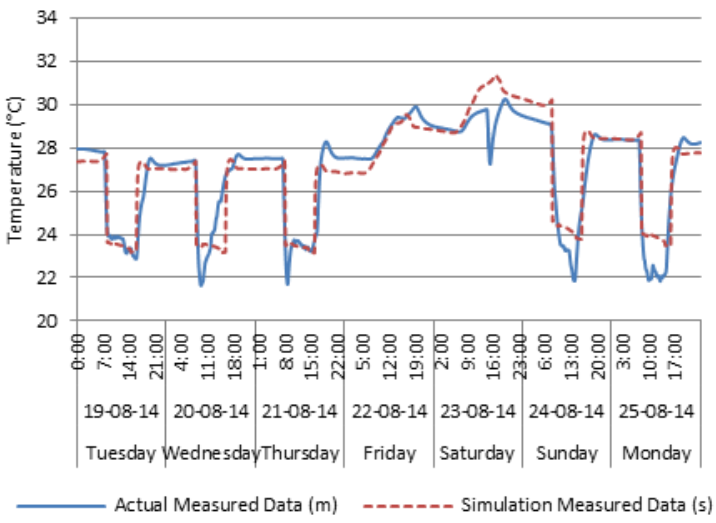

Figure 19. Inside room dry resultant temperature for; (a) whole week during winter, and (b) whole week during summer.

Figure 20 represents the model and measured total building lighting energy consumption monitored during July and August 2014, and combined Equipment and A/C energy model and measured consumption during July, September, October, November and December 2014. In general good agreement is achieved between the simulation results and measured data. Figure 21 shows the monthly energy consumption for calibrated model classified by category.

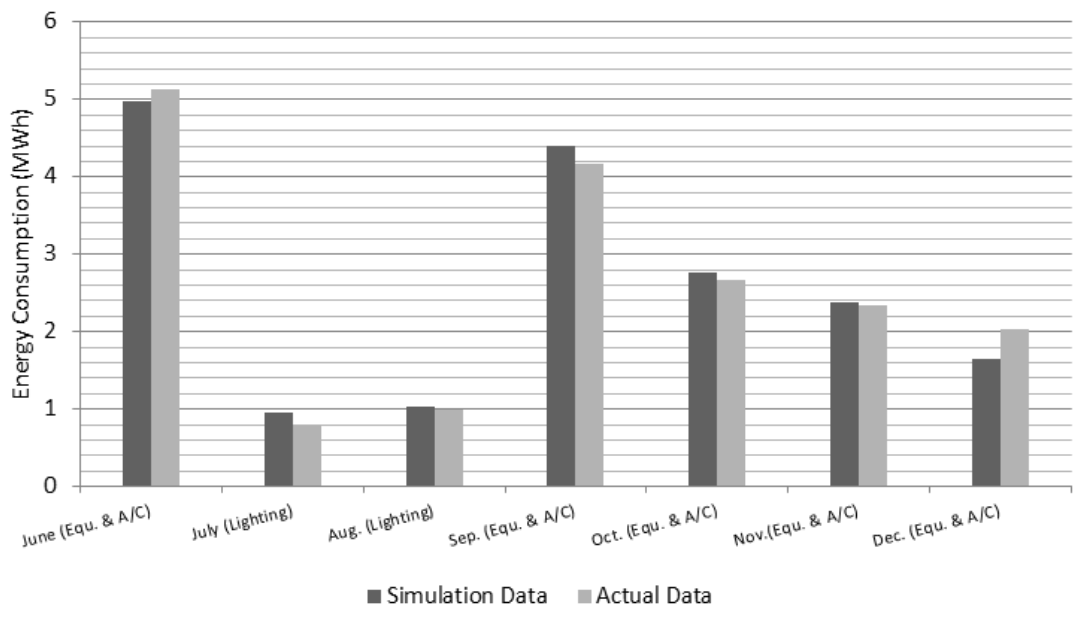

Figure 20. Sample of total equipment and lighting energy consumption.

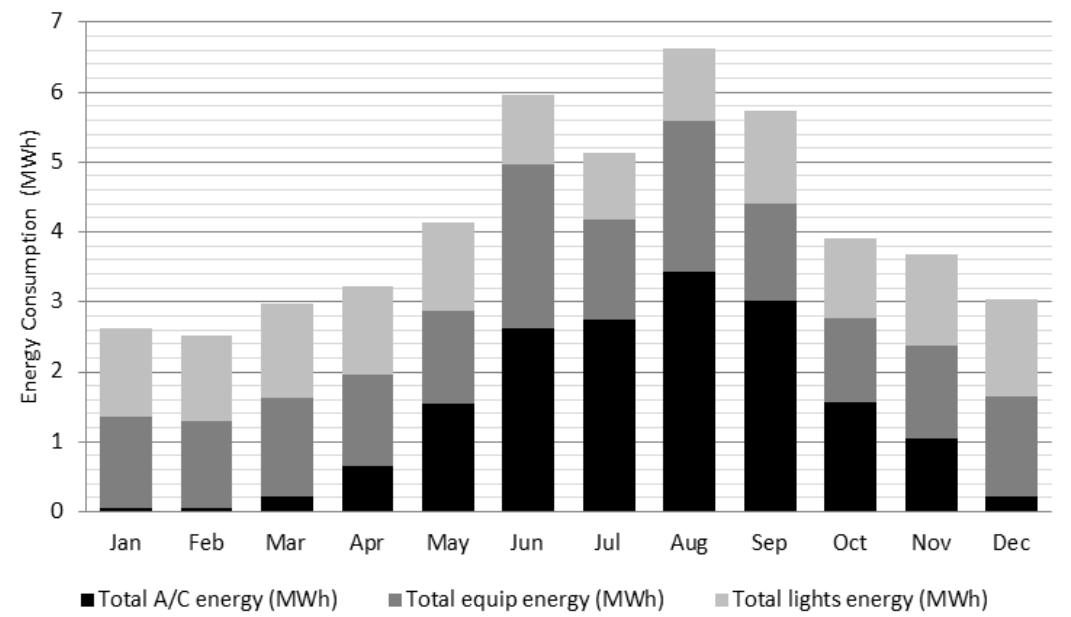

Figure 21. Monthly energy consumption for calibrated model classified by category. 
The calibrated model based on the average behaviour in the case study building during the monitoring period gives a useful output but is very specific to the context and may not be a good representation of the general performance of this type of building.

\section{GENERALISATION AND CONSIDERATION OF UNCERTAINTIES}

The monitoring and the model calibration process enabled the development of a model representative of the most commonly observed behaviour, indoor environment and energy use in the monitored case study building. However this calibrated model is very specific to the case study building and the specifics encountered during the monitoring period such as activities, behaviours, installed equipment, systems, operations, and weather. The calibrated model may not represent general buildings of this type, or may not represent well any buildings (including the monitored building) that have different specifics at any given time.

In order to address this issue the calibrated model was first reviewed against the more general survey data for buildings of this type, and adjusted to be more typical, then parameter sets were generated to capture likely variations in building specifics including operations and behaviour that could then be considered in assessing future energy consumption and indoor environmental performance of such buildings.

\subsection{Typical model creation}

The model has a different monthly energy use profile from the average observed in the general survey of type 2 offices reported in section 2, shown in Figure 22. The case study building has noticeably higher than average energy use in June and August, around top 25\% percentile of the surveyed offices, this may be associated with the intensive academic related activity in these periods which was noted during the survey. May and September also partly affected. During Ramadan this increased summer energy use appears to be offset by the observed shorter working hours. Energy use in the winter period is closer to the average of the surveyed offices, generally lying between the upper and lower 25th percentile around the mean.

To make the model more representative of the average performance seen in the general survey, a more consistent occupancy pattern was implemented, with summer activity levels reduced and winter activity levels increased. The other input parameters were also reviewed and in some cases adjusted to be closer to the mean value of the ranges established from the literature and used previously in the calibration process (Table 8). With these adjustments the model results matched more closely with the mean of the survey data for type 2 offices (Figure 22).

The typical model was re-run without cooling and the results compared against those for the type 1 offices in the survey, this also gave good agreement (Figure 23). Extension of the model to represent more intensively serviced office types is also readily do-able and will be the focus of further work.

Table 8 Primary input parameters and ranges (P.F. = Profile Factor).

\begin{tabular}{|c|c|c|c|c|c|c|}
\hline Parameter & Unit & $\begin{array}{c}\text { Contribution } \\
\text { to Power } \\
\text { Consumption }\end{array}$ & $\begin{array}{c}\text { Calibrated } \\
\text { Model }\end{array}$ & $\begin{array}{c}\text { Mean case } \\
\text { Model }\end{array}$ & $\begin{array}{l}\text { Best case } \\
(+3 \text { sigma })\end{array}$ & $\begin{array}{c}\text { Worst case } \\
\text { (-3 sigma) }\end{array}$ \\
\hline $\begin{array}{c}\text { Equipment load } \\
\text { (IT+Miscellaneous) }\end{array}$ & $\mathrm{W} / \mathrm{m}^{2}$ & Positive & 17.6 & 14.8 & 5.9 & 23.7 \\
\hline Equipment P.F. & --- & Positive & $0.6 / 0.9$ & 0.45 & 0.15 & 0.7 \\
\hline Lighting Load & $\mathrm{W} / \mathrm{m}^{2}$ & Positive & 12 & 10 & 4.0 & 16.0 \\
\hline Lighting P.F. & --- & Positive & $0.35 / 0.45$ & $0.3 / 0.5$ & 0.1 & 0.5 \\
\hline Occupancy Load & $\begin{array}{c}\mathrm{m}^{2} / \\
\text { person }\end{array}$ & Negative & 10 & 10 & 16 & 4.0 \\
\hline Occupancy P.F. & --- & Positive & $0.6 / 0.8$ & $0.45 / 0.6$ & 0.15 & 0.7 \\
\hline A/C Set point & ${ }^{\circ} \mathrm{C}$ & Negative & 21 & 22 & 26.0 & 18.0 \\
\hline A/C SEER eff & W/W & Negative & 6 & 8 & 14.0 & 2.0 \\
\hline $\begin{array}{c}\text { Infiltration Rate } \\
\text { (Operation) }\end{array}$ & $1 / \mathrm{s} . \mathrm{m}^{2}$ & Positive & \multirow{2}{*}{1} & 0.5 & 0.1 & 1.0 \\
\hline $\begin{array}{c}\text { Infiltration Rate } \\
\text { (Envelope) }\end{array}$ & $1 / \mathrm{s} . \mathrm{m}^{2}$ & Positive & & 0.3 & 0.3 & 0.3 \\
\hline
\end{tabular}



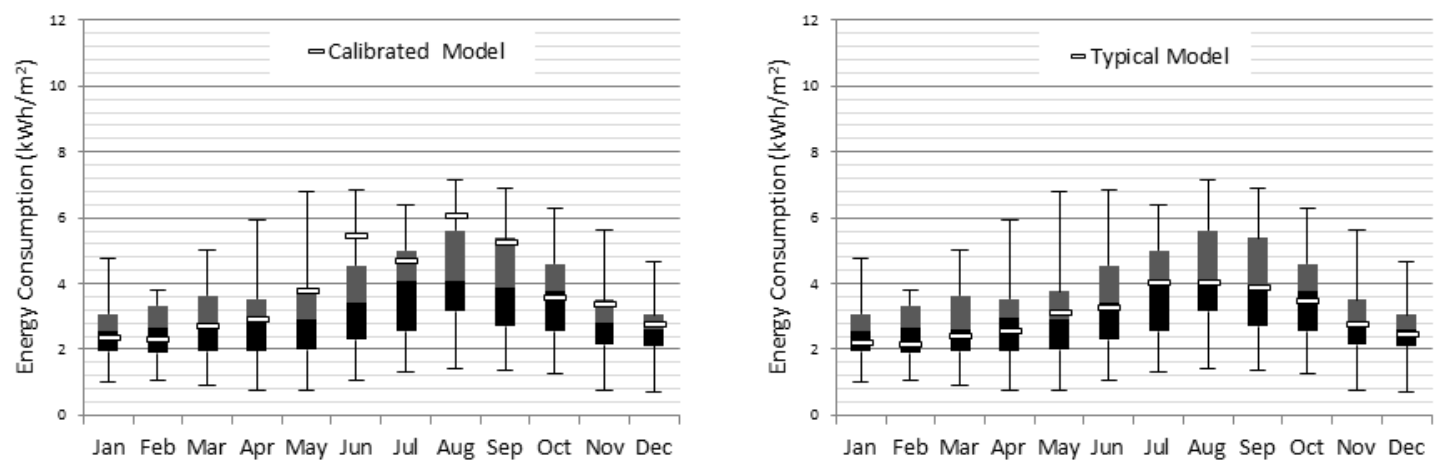

Figure 22. Monthly energy consumption for type 2 offices; (a) survey and calibrated model results, and (b) survey and typical model results.

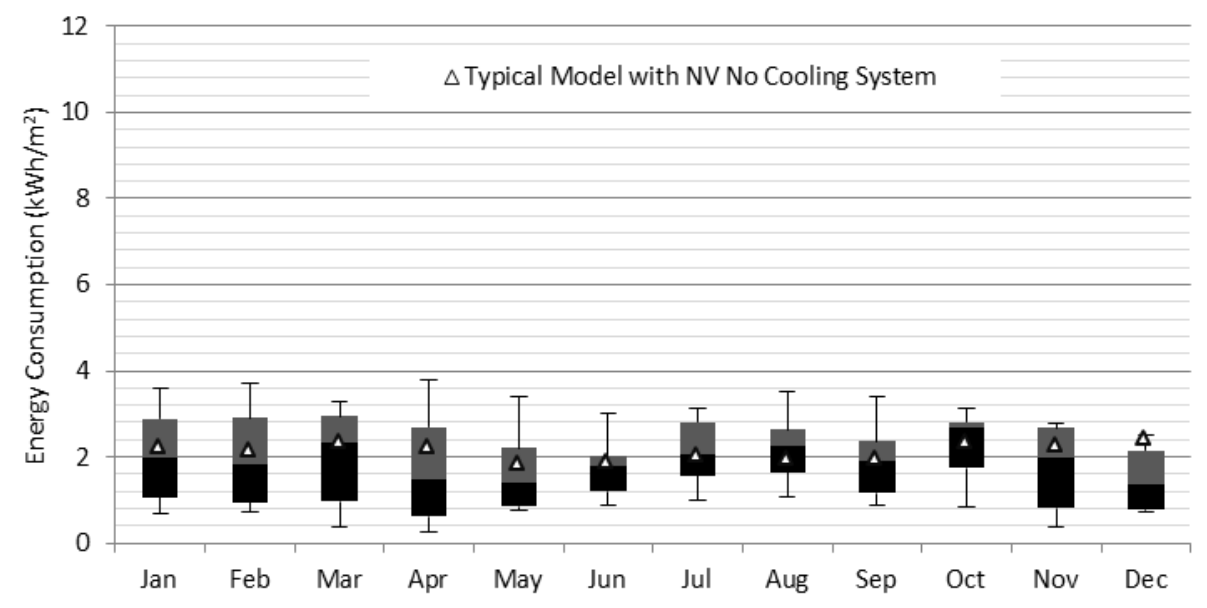

Figure 23 Monthly energy consumption for type 1 offices with Natural Ventilation (NV) and NO Cooling System: survey and typical model results.

\subsection{Realistic model input parameter sets capturing likely variations in operation and behaviour.}

To capture the inherent variability in operation and behaviour, 'best and worst case parameter sets' used in other industries to bracket likely ranges in input parameters were investigated [56]. The ranges previously established for the parametric screening were categorised in terms of their positive or negative influence on energy consumption e.g. increasing equipment loads will positively increase energy consumption, while increasing the cooling set point effect on energy consumption will be negative, and the extremes combined into 'best' and 'worst' case sets which drive low and high energy consumption respectively. The ranges were hypothesised to represent a notional $+/-3$ standard deviations i.e. this imposes a notional normal distribution on each parameter within these range limits, from which the standard deviations have then been determined (i.e. range divided by 6 ).

As the probability of occurrence of combinations where all 10 parameters are at the same time at the $+/-3$ deviation best or worst case settings together is very small, this is unrealistic and too extreme a situation to consider as a likely scenario in modelling, rather the situation where all 10 parameters are at $+/-1$ standard deviation best or worst case levels together is gives a more realistic spread, as represented in Figure 24.

These worst case parameter sets represent likely variations in operations and behaviours, there are obviously other factors such as weather and building fabric characteristics (such as insulation and glazing properties) which are uncertainties and will have some effect. The building fabric properties were found to have much smaller effects on energy consumption based on the parameter screening excercise and IC values than the worst case parameter sets of table 8 but this is based on a single case study building. Realistic worst case weather patterns could be readily established. 
The worst case model input parameter sets described here give some indication of likely effects of the most influential factors for building performance identified in the screening excercise and in part explain the variation seen in the survey. Of course the obvious intent would be to minimise the operational energy use through operating in the 'best case' situation however the realities such as constraints and competing demands for business productivity or improved comfort may not allow this. It is hoped the parameter sets here will allow such situations to be comprehended in modelling.

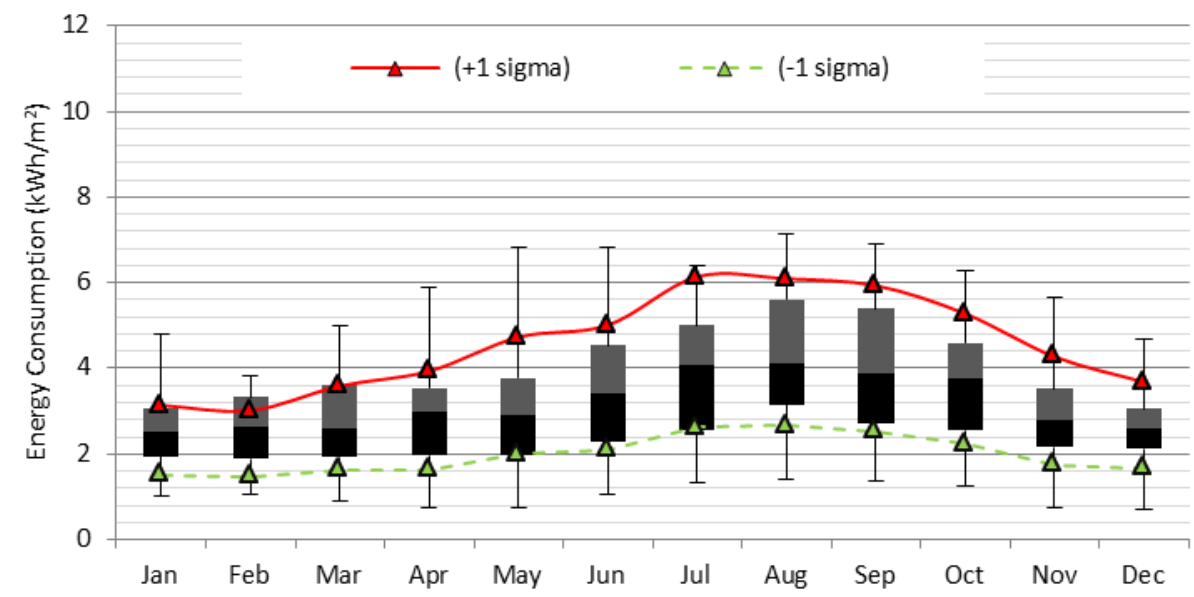

Figure 24. Realistic worst-case model input parameter sets for $+/-1$ standard deviation combinations superimposed on monthly energy consumption for Egyptian type 2 offices.

\section{DISCUSSION}

The main aims of the work were: (i) to provide insights into energy use and indoor environmental quality associated with current Egyptian office buildings, and (ii) to elaborate a methodology for producing a model to represent current Egyptian office performance to be used in future to inform upgrades and policy directions.

Both the multi-building energy survey and the detailed case study building evaluation give useful insights and add to the work of others in describing energy use and indoor environment in existing Egyptian buildings.

Interesting observations from the detailed survey of the existing office are on thermal comfort where people were observed to adjust their clothing rather than require heating in winter, also that people tended to control the temperature in the case study building to match with the expected temperatures in the PMV scale.

The methodology elaborated for creating first a calibrated model of an Egyptian office, then generalising this to form a more typical model, and developing realistic worst case model input parameter sets, appears to provide an interesting route to a baseline model which is grounded in measured data.

The modelling approach developed here has potential to inform new building standards, potential upgrades to existing buildings, or investigate policy options such as the Japanese Coolbiz initiative [57] or adoption of equipment or lighting energy efficiency standards etc.

Figure 25 illustrates how the typical model could potentially be used with the best and worst case occupancy and behaviour parameter sets and a similar dataset representing variation in weather conditions to illustrate performance across this range. Further work on weather files is needed to support such analysis. Views such as that in Figure 25 could be generated for different scenarios, e.g. upgrades, to allow performance impacts to be assessed. 


\begin{tabular}{|c|c|c|c|c|c|c|c|c|}
\hline \multirow{5}{*}{ 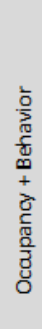 } & \multicolumn{4}{|c|}{ Total Energy $\left(\mathrm{kWh} / \mathrm{m}^{2}\right)$} & \multicolumn{4}{|c|}{ Summer PPD (\%) } \\
\hline & Worst (1 Sigma) & 50.4 & 53.0 & 55.9 & Worst (1 Sigma) & 13.2 & 14.4 & 18.8 \\
\hline & Typical & 35.0 & 36.5 & 38.6 & Typical & 12.2 & 13.7 & 18.6 \\
\hline & Best ( 1 sigma) & 23.3 & 24.3 & 25.8 & Best ( 1 sigma) & 12.8 & 14.5 & 19.8 \\
\hline & & Cool & Average & Warm & & Cool & Average & Warm \\
\hline & \multicolumn{4}{|c|}{ Weather } & \multicolumn{4}{|c|}{ Weather } \\
\hline
\end{tabular}

Figure 25 Performance view (annual energy use and summer thermal comfort percent of persons dissatisfied (PPD)) for a typical range of type 2 office buildings.

Both the energy survey, the case study building performance evaluation and the modelling process have been based on small datasets and this base should be expanded in future to give a more complete understanding.

Factors such as geometry, facade design etc. remain to be fully explored, although the parametric screening study appeared to indicate that geometry related building construction factors (e.g. U-values, glazing etc.) were less influential than operational and behavioural factors for the case study. The work here has focussed on office buildings and similar work could usefully be carried out for other building sectors.

It should be noted that it is always vitally important to continue to verify actual energy and indoor environmental performance of buildings, especially those with advanced technology options, as performance gaps have been found to be common and not yet fully addressed by the latest international initiatives [58],[59].

The work presented here is intended to provide some useful contributions to complement the work of others, and provide a platform for further work.

\section{CONCLUSIONS}

This paper provides insights into existing Egyptian building performance, and elaborates a process for developing a representative model.

The work presented is for office buildings but intended to be widely replicable.

An energy survey was carried out for 59 Egyptian offices, categorised by building service type, it was observed that energy use increases as building services increase, and existing Egyptian offices use less energy than benchmarks.

A more detailed investigation for a case study office was carried out to inform model calibration.

This provided insight into energy use, thermal comfort and environmental conditions, and revealed high variability in conditions and behaviours.

A calibrated model was created for the case study office, then a baseline model and input parameter sets created, to represent more generalised performance.

Future uses of the methodology, including assessing the impact of codes are discussed and further replication potentials highlighted.

\section{REFERENCES}

1. $\quad$ Eberhard, A., et al., Underpowered: the state of the power sector in Sub-Saharan Africa. Background paper, 2008. 6.

2. ECP306/1-2005, The Egyptian Residential Buildings Energy Code. Housing and Building National Research Center, HBRC 2005 Egypt.

3. Zhou, Y., et al., Modeling the effect of climate change on US state-level buildings energy demands in an integrated assessment framework. Applied Energy, 2014. 113: p. 1077-1088.

4. Raslan, R.M.S., Performance based regulations: the viability of the modelling approach as a methodology for building energy compliance demonstration. 2010, UCL (University College London).

5. Standard, A., 90.1-2013 'Energy Standard for Buildings Except Low-Rise Residential Buildings'. 2013. 

Center, HBRC 2005 Egypt.

7. Council, U.G.B., LEED: Leadership in energy and environmental design. 2011.

8. $\quad$ system, E.G.B.C.T.G.P.r., Egyptian Green Building Council The GREEN PYRAMID rating system. 2009, Egypt.

9. $\quad$ Clarke, J.A., Energy simulation in building design. 2001: Routledge.

10. Reddy, T.A. and K.K. Andersen, An evaluation of classical steady-state off-line linear parameter estimation methods applied to chiller performance data. HVAC\&R Research, 2002. 8(1): p. 101-124.

11. Zhao, H.-x. and F. Magoulès, A review on the prediction of building energy consumption. Renewable and Sustainable Energy Reviews, 2012. 16(6): p. 3586-3592.

12. Attia, S., A tool for design decision making: zero energy residential buildings in hot humid climates. Vol. 4. 2012: Presses univ. de Louvain.

13. Crawley, D.B., Building Performance Simulation: A Tool For Policymaker, in Mechanical And Aerospace Engineering. 2008, Strathclyde University.

14. Coakley, D., P. Raftery, and M. Keane, A review of methods to match building energy simulation models to measured data. Renewable and Sustainable Energy Reviews, 2014. 37: p. 123-141.

15. Recast, E., Directive 2010/31/EU of the European Parliament and of the Council of 19 May 2010 on the energy performance of buildings (recast). Official Journal of the European Union, 2010. 18(06): p. 2010.

16. Baldwin, R., et al., BREEAM 98 for Offices. Building Research Establishment, Watfordt, 1998.

17. Crawley, D.B., et al., Contrasting the capabilities of building energy performance simulation programs. Building and environment, 2008. 43(4): p. 661-673.

18. Attia, S., et al., Selection criteria for building performance simulation tools: contrasting architects' and engineers' needs. Journal of Building Performance Simulation, 2012. 5(3): p. 155-169.

19. $\quad$ Enviroment, I.-V.I.E.S.-V., Dynamic Simulation tool. 2014.

20. Fabrizio, E. and V. Monetti, Methodologies and advancements in the calibration of building energy models. Energies, 2015. 8(4): p. 2548-2574.

21. Reddy, T.A., I. Maor, and C. Panjapornpon, Calibrating detailed building energy simulation programs with measured data-Part I: General methodology (RP-1051). Hvac\&R Research, 2007. 13(2): p. 221-241.

22. Guideline, A., Guideline 14-2002, Measurement of Energy and Demand Savings. American Society of Heating, Ventilating, and Air Conditioning Engineers, Atlanta, Georgia, 2002.

23. Coakley, D., et al. Calibration of a detailed BES model to measured data using an evidence-based analytical optimisation approach. in Proceedings of the 12th International IBPSA Conference. Sydney, Australia. 2011.

24. Raftery, P., M. Keane, and A. Costa, Calibrating whole building energy models: Detailed case study using hourly measured data. Energy and Buildings, 2011. 43(12): p. 3666-3679.

25. Elharidi, A.M., et al., Calibration Of Numerical Simulations Modeling Of Nonresidential Building In Hot Humid Climate Region. 2015.

26. Cooper, I., Post-occupancy evaluation-where are you? Building Research \& Information, 2001. 29(2): p. 158-163.

27. Energy, A., Energy consumption guide 19: energy use in offices. Energy, 2003.

28. EIA, U., International energy outlook 2013. US Energy Information Administration (EIA), 2013.

29. NCM, National Calculation Methodology (NCM) Modeling Guide (for buildings other than dwellings in England and Wales), Building Research Establishment Ltd, 2011., in 20th November 2015: Release of iSBEM_v5.2.g. 2011.

30. Abd-Allah, N.R., et al., Energy Conservation in Existing Office Building: Case study Petrojet Company Head Office Buildings in Cairo, Egypt. 2014.

31. Ezzeldin, S.M.N., Mixed-Mode Cooling Design for Office Buildings in Arid Climates, Ph.D. Thesis. 2011, De Montfort University: De Montfort University.

32. Attia, S.G.M., et al., Towards strategic use of BPS tools in Egypt. IBPSA, 2011. 1.

33. Attia, S., A. Evrard, and E. Gratia, Development of benchmark models for the Egyptian residential buildings sector. Applied Energy, 2012. 94: p. 270-284.

34. Elharidi, A.M., P.G. Tuohy, and M.A. Teamah. Facing the growing problem of the electric power consumption in Egyptian residential building using building performance simulation program. in Building Simulation Cairo 2013 Conference. 2013. 
35. Mahdy, M.M. and M. Nikolopoulou, Evaluation of fenestration specifications in Egypt in terms of energy consumption and long term cost-effectiveness. Energy and Buildings, 2014. 69: p. 329-343.

36. Dabaieh, M., et al., Reducing cooling demands in a hot dry climate: A simulation study for non-insulated passive cool roof thermal performance in residential buildings. Energy and Buildings, 2015. 89: p. 142-152.

37. ElDabosy, M.M. and M.M. AbdElrahman, Evaluation of Office Spaces Ventilation using Simulation software ElDakahlia Governmental Headquarter as a Pilot Renovation. 2013.

38. El Mohimen, M.A., G. Hanna, and M. Krarti, Analysis of daylighting benefits for office buildings in Egypt. Journal of solar energy engineering, 2005. 127(3): p. 366-370.

39. Saleem, A., et al., An Analysis of Thermal Comfort and Energy Consumption within Public Primary Schools in Egypt. 2016.

40. Sheta, W. and S. Sharples. A Building Simulation Sustainability Analysis to Assess Dwellings in a New Cairo Development. in Fourth National Conference of IBPSA-USA, New York City, New York. 2010.

41. Hanna, G.B., Energy Analysis for New Office Buildings in Egypt. 2013.

42. Attia, S., A tool for design decision making: zero energy residential buildings in hot humid climates, Ph.D. Thesis. 2012, Presses univ. de Louvain.

43. Westphal, F.S. and R. Lamberts. Building simulation calibration using sensitivity analysis. in Ninth International IBPSA Conference. 2005. Citeseer.

44. Ashrae, A., Standard 55-2004, Thermal environmental conditions for human occupancy. American Society of Heating, Refrigerating and Air-Conditioning Engineering, Atlanta, GA, 2004.

45. Nicol, F. and M. Humphreys, Derivation of the adaptive equations for thermal comfort in free-running buildings in European standard EN15251. Building and Environment, 2010. 45(1): p. 11-17.

46. Taleghani, M., et al., A review into thermal comfort in buildings. Renewable and Sustainable Energy Reviews, 2013. 26: p. 201-215.

47. de Dear, R.J. and G.S. Brager, Thermal comfort in naturally ventilated buildings: revisions to ASHRAE Standard 55. Energy and buildings, 2002. 34(6): p. 549-561.

48. Fanger, P.O., Thermal comfort. Analysis and applications in environmental engineering. Thermal comfort. Analysis and applications in environmental engineering., 1970.

49. Cen, E., 15251, Indoor environmental input parameters for design and assessment of energy performance of buildings addressing indoor air quality, thermal environment, lighting and acoustics. European Committee for Standardization, Brussels, Belgium, 2007.

50. $\quad$ Elharidi, A.M. and P.G. Tuohy, Capturing Uncertainty in Operation, Behavior and Weather in Building Performance Assessment: An Egyptian Case Study., in 9th Windsor Conference. 2016: Cumberland Lodge, Windsor, UK.

51. Robaa, S., Evaluation of sunshine duration from cloud data in Egypt. Energy, 2008. 33(5): p. 785-795.

52. https://energyplus.net/weather-location/africa_wmo_region_1/EGY//EGY_Alexandria.623180_ETMY.

53. Zhang, Q., J. Huang, and S. Lang, Development of typical year weather data for Chinese locations/Discussion. ASHRAE transactions, 2002. 108: p. 1063.

54. Royapoor, M. and T. Roskilly, Building model calibration using energy and environmental data. Energy and Buildings, 2015. 94: p. 109-120.

55. Heo, Y., R. Choudhary, and G. Augenbroe, Calibration of building energy models for retrofit analysis under uncertainty. Energy and Buildings, 2012. 47: p. 550-560.

56. Iqbal, I. and M.S. Al-Homoud, Parametric analysis of alternative energy conservation measures in an office building in hot and humid climate. Building and environment, 2007. 42(5): p. 2166-2177.

57. Haneda, M., et al., A field measurement of thermal environment in COOL BIZ office and the evaluation on productivity by a questionnaire survey. Journal of Environmental Engineering, 2009. 74(637): p. 389-396.

58. Tuohy, P.G. and G.B. Murphy, Are current design processes and policies delivering comfortable low carbon buildings? Architectural Science Review, 2015. 58(1): p. 39-46.

59. Tuohy, P.G. and G.B. Murphy, Closing the gap in building performance: learning from BIM benchmark industries. Architectural Science Review, 2015. 58(1): p. 47-56. 